PostScript

\section{Merkel cell carcinoma of the eyelid in association with chronic lymphocytic leukaemia}

Merkel cell carcinoma (MCC) is a rare skin neoplasm. Tang and Toker ${ }^{1}$ first described MCC in 1978 and since then 19 cases in association with chronic lymphocytic leukaemia (CLL) have been reported..$^{2-5}$ To the best of our knowledge, involvement of the eyelid by MCC has never been reported in the literature in association with CLI.

\section{Case report}

An 84 year old white man was referred with an 8 week history of a painless lump on his right upper eyelid (Fig lA). He was complaining of visual obscuration secondary to a mechanical ptosis. Ophthalmic history was unremarkable and specifically there were no previous chalazions or trauma. On examination a firm lesion of the right eyelid measuring $2 \times 1 \mathrm{~cm}$ with overlying telangiectatic ves sels and sparing of the eyelashes was noted (Fig 1A). Further ophthalmic examination was unremarkable. General examination did not reveal any abnormalities.

General medical history revealed that the patient had been diagnosed with CLL 1 months previously and was being treated with pulsed chlorambucil. His condition was considered to be stable by his oncologist. At the time he had a white cell count of $15.7 \times 10^{9} / 1$ These consisted of immature lymphocytes of a B cell lineage. A full thickness incisional biopsy was performed under local anaesthesia. Histopathological examination of the biopsy sample showed an intact epidermis with the underlying dermis being infiltrated by clumps of a small cell tumour (Fig 2A).
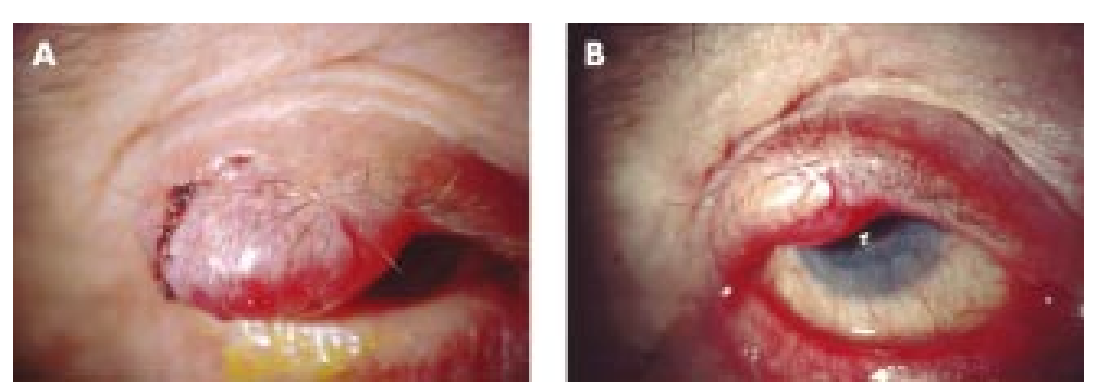

Figure 1 (A) Merkel cell tumour involving most of the upper lid causing mechanical ptosis and visual obscuration. Biopsy site is seen laterally. (B) Merkel cell tumour after treatment with radiotherapy.
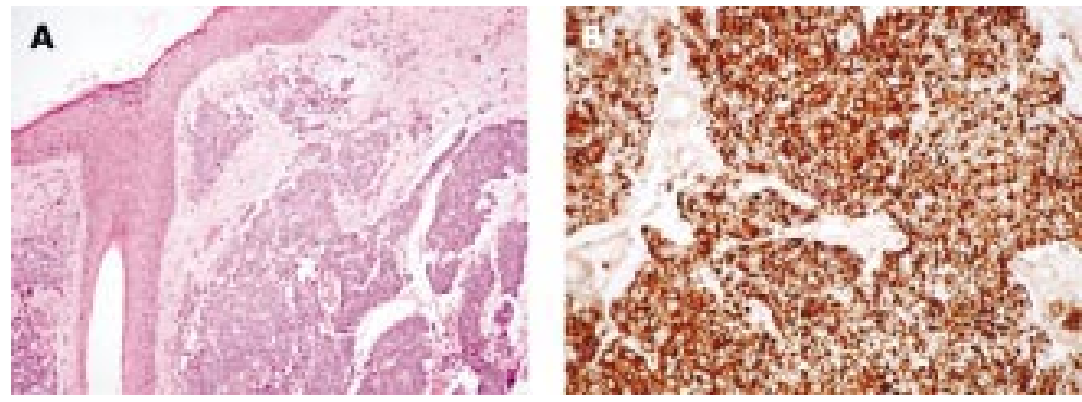

Figure 2 (A) Haematoxylin and eosin stain Merkel cell tumour. (B) Immunostaining with CAM5.2 showing characteristic para-nuclear accentuation.

Immunostaining showed the tumour cells were negative for LCA (leucocyte common marker), chromogranin, and S100 antigens. The tumour cells were positive for NSE (neuron specific enolase), EMA (epithelial membrane antigen) and CAM 5.2, which showed characteristic paranuclear accentuation (Fig the tumour cells to be in features are consistent with the diagnosis of MCC.

Further investigation revealed no systemic metastasis. We opted for radiotherapy as the patient was reluctant to have surgical intervention. The patient was given a total of $40 \mathrm{~Gy}$ in 15 fractions. This caused the tumour to (Fig 1B)

\section{Comment}

The recent surveillance, epidemiology, and end results (SEER) programme ${ }^{5}$ in the United States has estimated the incidence of MCC at $0.23 / 100000$. MCC is very rare below the age sites. It is an aggressive tumour with 12-45\% being lymph node positive at presentation. to $55-79 \%$ during the course of the disease. The 5 year survival has been reported at 30-64\%. ${ }^{67}$ Involvement of the eyelid occurs in only $0.8 \%$ of MCC, ${ }^{5}$ and has no with CLL.

Secondary tumours are common in B cell neoplasia with the relative risk of nonmelanotic skin cancer being 4.7 in men and 2.4 in women. ${ }^{8}$ The frequency and aggressive ness of MCC and other skin neoplasms increases with immunosuppression, organ 


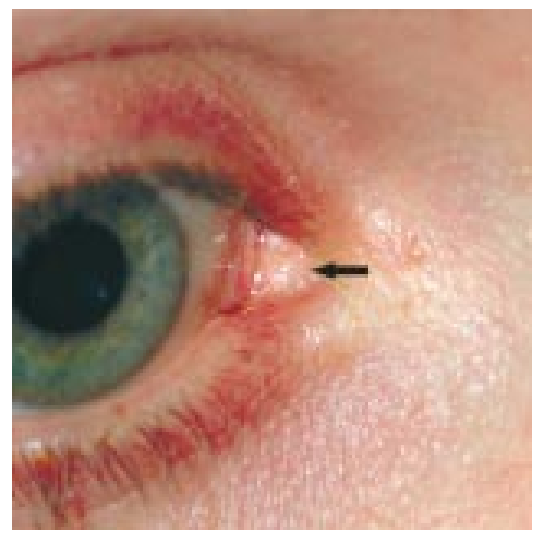

Figure 1 Clinical appearance of the pale yellow lesion of the right caruncle (arrowed).

lacrimal tissue. Consequently, the caruncle may develop a tumour or cyst similar to one found in the skin, conjunctiva, or lacrimal gland.

\section{Case report}

A 26 year old woman presented with a $2 \mathrm{~mm}$, asymptomatic, pale yellow lesion of the right caruncle, present for 8 months (Fig 1). It was excised intact under local anaesthetic and histological examination revealed a cyst lined by stratified squamous epithelium and containing sebaceous glands in its wall (Fig 2). These communicated directly with the cyst lumen. No associated hair follicles were seen. An eosinophilic, crenulated cuticle was present on the inner aspect of the cyst wall in some areas. The patient had no other skin lesions of note. The nails, teeth and hair were normal. There was no family history of similar lesions. At the 6 month follow up there have been no signs of recurrence or development of other cysts.

The diagnosis was of steatocystoma simplex (SS) of the caruncle.

\section{Comment}

Steatocystoma simplex, the non-heritable solitary counterpart of steatocystoma multiplex (SM), was first described as a distinct entity by Brownstein in 1982. 'It is a benign

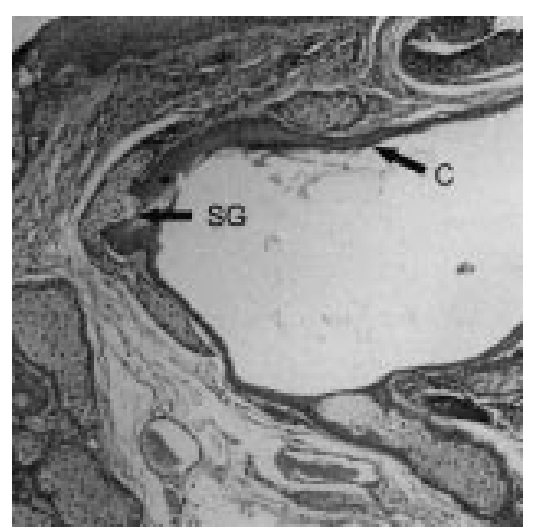

Figure 2 Histological examination reveals a cyst, lined by stratified squamous epithelium with an eosinophilic cuticle on the inner aspect $(\mathrm{C})$ and sebaceous glands in the cyst wall communicating directly with the lumen (SG). The diagnosis is steatocystoma. (Original magnification $\times 100$, haematoxylin and eosin.) adnexal tumour, thought to originate from a naevoid malformation of the pilosebaceous duct junction. ${ }^{2}$

Lesions are described on the forehead, nose, scalp, neck, axillae, chest, upper limbs, back, legs, ${ }^{1}$ and even intraorally. ${ }^{3}$ To our knowledge though, steatocystoma has not previously been reported in the caruncle. ${ }^{45}$

Thirty two cases of SS are reported in the literature, divided evenly between men and women and ranging in age from 15 to 70 years. ${ }^{136}$ Clinical and histological features in SS are usually identical to those seen in the individual lesions of SM. Lesions are described as asymptomatic, flesh coloured or yellowish, intracutaneous, well circumscribed, soft, mobile, and non-tender. On incision they are found to contain an oily substance composed of sebum. ${ }^{1}$

However, it is important to confirm the solitary nature of a steatocystoma. SM can be familial and autosomal dominantly inherited (steatocystoma multiplex congenita). ${ }^{7}$ Several familial cases have been linked to pachyonichia congenita and ectodermal dysplasia through a mutation in keratin $17 .{ }^{8}$ It has been associated with hypothyroidism, hypohidrosis, hypotrichosis and hypertrophic lichen planus, ichthyosis, and koilonychia.' SM may be progressive with inflamed cysts, rupturing, and healing with scars. ${ }^{7}$

Steatocystoma is histologically characterised by a cystic structure with sebaceous glands within the cyst wall and epithelium that displays an eosinophilic cuticle. It is possible to make a diagnosis of steatocystoma if the characteristic hyaline luminal cuticle is present, even in the absence of sebaceous elements.

The differential diagnosis included sebaceous gland hyperplasia, sebaceous gland adenoma, and lipogranuloma. Clinically they are also characterised by a yellow, nodular appearance. ${ }^{5}$ Rarely, sebaceous gland carcinoma of the caruncle may occur. ${ }^{5}$ Along with hidrocystoma and eruptive vellus hair cyst they can usually be excluded histologically. Oncocytomas are asymptomatic, slowly progressive, solid or cystic masses but usually described as reddish blue/tan. ${ }^{45}$

Most treatment regimens for steatocystoma reflect the multiplicity and widespread extent of lesions of SM. Oral isotretinoin has been used to reduce associated inflammation. Cryosurgery, carbon dioxide laser, and incision with removal of the cyst wall have been employed. ${ }^{70}$ We felt the best way to manage this solitary lesion arising in the caruncle was by simple excision with removal of the cyst wall intact, thereby reducing the risk of recurrence. We were able to confirm the unique nature of this lesion and rule out malignancy.

J Bowyer, T Sullivan

The Eyelid, Lacrimal and Orbital Clinic, Division of Ophthalmology, Department of Surgery, Royal Brisbane Hospital, Herston Road, Herston, Brisbane, Qld, 4029, Australia

K Whitehead

Sullivan Nicolaides and Partners, 134 Whitmore Street, Taringa, Qld, 4068, Australia

Correspondence to: Dr T Sullivan; tj@@gil.com.au Accepted for publication 24 June 2002

\section{References}

1 Brownstein MH. Steatocystoma simplex; a solitary steatocystoma. Arch Dermatol 1982; 118:409-11.

2 Requena L, Sanchez Yus E. Follicular hybrid cysts; an expanded spectrum. Am J Dermatopathol 1991;13:228-33.
3 Olson DB, Mostofi RS, Lagrotteria LB. Steatocystoma simplex in the oral cavity: a previously undescribed condition. Oral Surgery Oral Med Oral Pathol 1988;66:605-7.

4 Luthra CL, Doxanas MT, Green WR. Lesions of the caruncle. A clinicopathological study. Surv Ophthalmol 1978;23:183.

5 Shields CL, Shields JA, White D, et al. Types and frequency of lesions of the caruncle. Am J Ophthalmol 1986;102:7721-8.

6 Nakamura S, Nakayama K, Hoshi K, et al. A case of steatocystoma simplex on the head. J Dermatol 1988;15:347-8.

7 Pamoukian VN, Westreich M. Five generations with steatocystoma multiplex congenita: a treatment regimen. Plastic Reconstruct Surg 1997;99:1 142-6.

8 Feinstein A, Friedman J, Schewach-Millet M. Pachyonychia congenita. J Am Acad Dermatol 1988;19:705-11

9 Sohn D, Chin TCM, Fellner M. Multiple keratoacanthomas associated with steatocystoma multiplex and rheumatoid arthritis. Arch Dermatol 1980;116:913-4.

10 Krahenbuhl A, Eichmann A, Pfaltz M. $\mathrm{CO}_{2}$ laser therapy for steatocystoma multiplex. Dermatologica 1991;183:294-6.

\section{Preliminary results with posterior lamellar keratoplasty for endothelial failure}

We describe the technique and the results of three cases where we performed a posterior lamellar keratoplasty.

\section{Case reports}

The following surgical technique was performed in all cases. The donor posterior button was obtained from an entire fresh globe. We made sure that intraocular pressure was adequate by injecting BSS (balanced salt solution, Alcon) in the vitreous cavity. With a Moria ONE microkeratome, an anterior cap of $250 \mu \mathrm{m}$ was cut and lifted. A Barron trephine $7 \mathrm{~mm}$ in diameter was used to obtain the posterior button, covered afterwards with viscoelastic to protect it and to avoid desiccation.

With our microkeratome an $8.5 \mathrm{~mm}$ in diameter, nasal hinge and $250 \mu \mathrm{m}$ flap was obtained. The trephination was made with a 7 mm Barron trephine and completed with corneal scissors, under viscoelastic protection.

After the intraocular injection of acetylcholine the posterior donor button was placed on the recipient eye under viscoelastic protection. Six 10-0 Nylon interrupted sutures were used to secure and close the wound. Immediately after, the flap was put back and fixated with six interrupted 10-0 Nylon sutures and the knots were buried. The viscoelastic anterior chamber was exchanged with BSS using an automatic pressure controlled irrigationaspiration system.

\section{Case 1}

This was a 36 year old woman with Fuchs' endothelial dystrophy. Preoperative BSCVA was 0.4 in the right eye and 0.6 in the left. Slit lamp examination showed diffuse corneal oedema clearly affecting the anterior layers of the cornea. Endothelial cell count (ECC) was below 900 cells $/ \mathrm{mm}$ in both eyes. Surgery was performed on the right eye (Fig 1A). The follow up was done for 12 months (Fig 1B).

\section{Case 2}

Case 2 was a 57 year old man with Fuchs' endothelial dystrophy. Preoperative BSCVA was 0.1 in the right eye and 0.06 in the left. Slit lamp examination showed diffuse stromal corneal oedema in the left surgical eye. ECCs were difficult to perform because of the light 

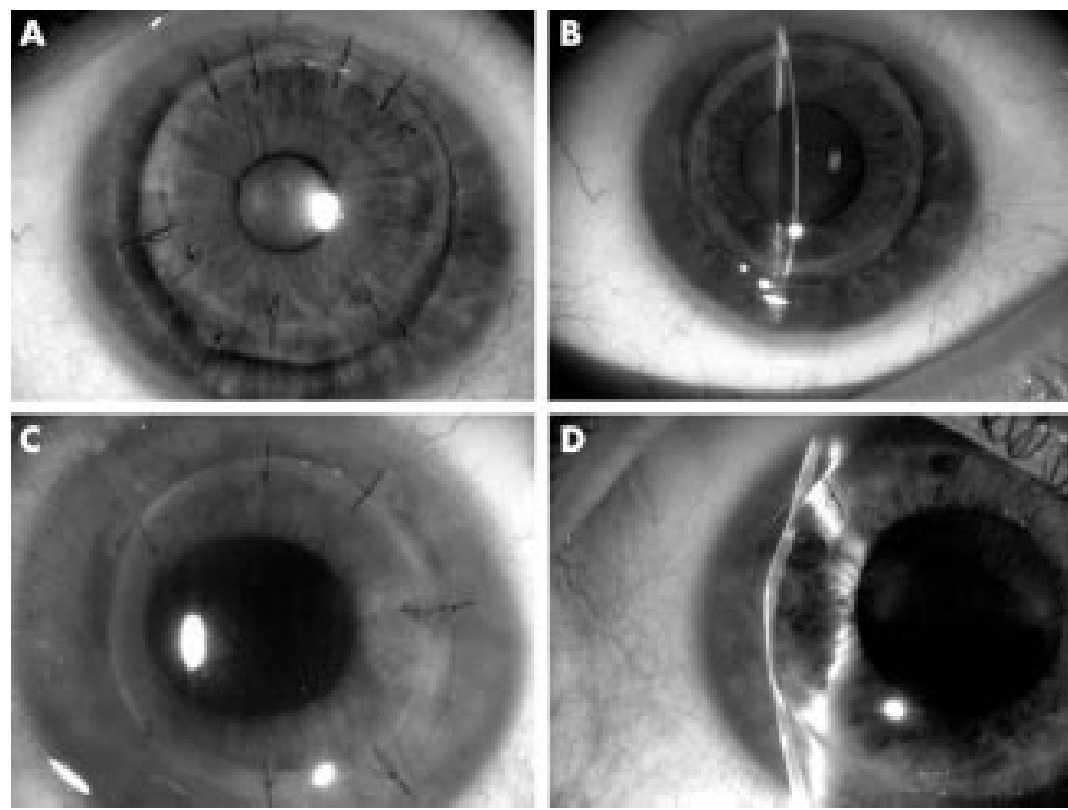

Figure 1 (A) Photography of case 1 at 1 week after posterior lamellar keratoplasty. (B) Case 1 at 12 months after posterior lamellar keratoplasty. (C) Case 2 at 3 months after posterior lamellar keratoplasty.(D) Case 3 at 6 months after posterior lamellar keratoplasty.

scattering induced by the oedema but were below $800 \mathrm{cell} / \mathrm{mm}$ in both eyes. The patient's case was followed for 12 months (Fig 1C)

\section{Case 3}

This was a 57 year old man with history of myopia in both eyes (right eye -4.00 , left eye -9.00 ). There was a history of subretinal macular neovascularisation and cataract extraction in his left, surgical, eye, with an ECC of $950 \mathrm{cell} / \mathrm{mm}$. Preoperative BSCVA was 0.5 in the right eye and 0.2 in the left. The follow up was done during 14 months (Fig lD).

Examinations in all cases were at day 1,1 week, 3, 6, 9, and 12 months. All Nylon sutures were removed before the 6 month control.

All surgeries were technically uneventful. The immediate and late postoperative controls showed transparency of the cornea and no signs of rejection. In case $l$ at the time of removing the superior suture ( 3 months postoperatively) a separation between the anterior cap and the edge of the corneal recipient eye was observed (because of the stromal flap oedema) and two interrupted 10-0 Nylon suture were placed for 3 more months.

Uncorrected and BSCVA did not improve in all cases in spite of corneal transparency (Table 1). We observed a significant increase in astigmatism in all cases during the follow up and also after the suture removal, ${ }^{1}$ but it was not the main cause of reduced vision (Table 2 ). We checked vision changes with refraction over rigid gas permeable lenses but the results were lower than expected.

\section{Comment}

Many attempts have been made to independently replace the endothelial layer. First Mohay $^{2}$ and McCulley $^{3}$ used eyes of the animal models and obtained successful results. Later, Melles et al described a surgical technique in which through a scleral tunnel incision a mid-stromal pocket was dissected to separate and transplant the posterior stroma $^{4}$ Ehlers $^{5}$ and Busin, ${ }^{6}$ using a microkeratome to access the posterior cornea, also had similar results. We used the open technique as described by Busin, but suturing both corneal layers, and our cases showed a significant astigmatism and very low visual results.

Reviewing our experience during the past 6 years in performing penetrating keratoplasty (PK) for Fuchs's dystrophy, and obviously understanding that this is not a comparative study, we realised that our mean improvement in best corrected visual acuity was 3.1 lines (range 0-8), with a mean postoperative time for visual rehabilitation of 8 months (range 3-18 months).

The recovery time was slower when compared with PK, perhaps because of the optical distortion of the interface. We must also not forget that we sutured both the donor button and the superficial lenticule, perhaps inducing interface distortion. Also it is important to mention the risk of wound leakage and interface aqueous humour dissection.

We think that the time of graft deswelling was not as expected because at the time of suture removal a separation was noted between the anterior cap and the recipient eye in cases 1 and 2 . We placed sutures in this site but the time of suture removal was extended to 12 months. Another contributing factors would be host-graft disparity, trephination, and suture technique

In our experience this technique shows that it is possible to change only the posterior layers of the cornea with successful anatomical result. Nevertheless, from a functional perspective penetrating keratoplasty has been a much better and faster approach and, in fact, in both techniques we are replacing the endothelium using an open sky technique.

J L. Güell, F Velasco, E Guerrero, O Gris Cornea and Refractive Surgery Department, "Instituto de Microcirugía Ocular," Barcelona, Spain

M Calatayud

Cornea and Refractive Surgery Unit, University Hospital, Vall d' Hebron, Barcelona, Spain

Correspondence to: Jose L Güell, MD, PhD, Instituto de Microcirugía Ocular, Departamento de Cornea, c/Munner 10, 10 CP 08022, Barcelona Spain; guell@imo.es

Accepted for publication 17 July 2002

Table 1 Best corrected visual acuity before and after the endokeratoplasty

\begin{tabular}{|c|c|c|c|c|c|c|}
\hline & Preoperative & 2 Weeks & 3 Months & 6 Months & 9 Months & 12 Months \\
\hline Case 1 & 0.5 & $\begin{array}{l}\text { Counting fingers to } 1 \\
\text { metre }\end{array}$ & 0.1 & 0.1 & 0.32 & 0.5 \\
\hline Case 2 & 0.63 & 0.1 & 0.3 & 0.3 & 0.3 & 0.5 \\
\hline Case 3 & $\begin{array}{l}\text { Counting fingers } 0.5 \\
\text { metre }\end{array}$ & $\begin{array}{l}\text { Counting fingers } 0.5 \\
\text { metre }\end{array}$ & $\begin{array}{l}\text { Counting fingers } 0.5 \\
\text { metre }\end{array}$ & $\begin{array}{l}\text { Movements of hands } \\
0.5 \text { metre }\end{array}$ & $\begin{array}{l}\text { Movements of hands } \\
0.5 \text { metre }\end{array}$ & $\begin{array}{l}\text { Movements of hands } \\
0.5 \text { metre }\end{array}$ \\
\hline
\end{tabular}

Table 2 Astigmatism before and after of endokeratoplasty

\begin{tabular}{lllllll}
\hline & Preoperative & 2 weeks & 3 months & 6 months & 9 months & 12 months \\
\hline Case 1 & -0.75 & -7.00 & -7.50 & -8.50 & -9.50 & -6.00 \\
Case 2 & -2.00 & -3.00 & -4.00 & -5.00 & -6.50 & -5.00 \\
Case 3 & -0.5 & -3.00 & -4.00 & -4.00 & -3.50 & -3.50 \\
\hline
\end{tabular}


References

1 Pineros O, Cohen EJ, Rapuano CJ, et al. Long-term results after penetrating keratoplasty for Fuch's endothelial dystrophy. Arch Ophthalmol 1996;114:15-18

2 Mohay J, Lange T, Soltau J, et al. Transplantation of corneal endothelial cells using a cell carriers device. Cornea 1994:13:173-82.

3 McCulley JP, Maurice DM, Schwartz BD Corneal endothelium transplantation. Ophthalmology 1980;87:194-201.

4 Melles G, Lander F, Beekhuis W, et al. Posterior lamellar keratoplasty for a case of pseudophakic bullous keratopathy. Am J Ophthalmol 1999; 127:340-1

5 Ehlers K, Ehlers H, Hiortdal J, et al. Grafting of the posterior cornea. Description of a new technique with 12-month clinical results. Acta Ophthalmol Scand 2000;78:543-6.

6 Busin M, Arffa R, Sebastián A. Endokeratoplasty as an alternative to penetrating keratoplasty for the surgical treatment. Ophthalmology 2000;107:207782.

\section{Persistent accommodative spasm after severe head trauma}

Spasm of accommodation is the sudden development of a considerable degree of myopia which disappears after cycloplegia, usually functional in origin. ${ }^{1}$ Bohlmann and France reported a patient with persistent spasm of accommodation 9 years after head trauma and suggested that a possible lesion in the upper brainstem might be responsible for the dysfunction. We report two similar cases in which magnetic resonance imaging (MRI) failed to show abnormalities in the mid-brain and revealed cerebellar and supratentorial traumatic lesions.

\section{Case reports}

Case 1

A 34 year old female patient came to the refractive surgery service for correction of myopia and astigmatism. She had been comatose for 45 days after suffering severe head injury at the age of 24 , and 3 months later noticed difficulties in her distant vision and was prescribed corrective lenses.

Dynamic refraction revealed in the right eye $-3.75 \mathrm{sph}-1.50 \mathrm{cyl} \times 5$ and in the left eye $-3.50 \mathrm{sph}-1.00 \mathrm{cyl} \times 170$. Visual acuity was 20/25 in each eye with this correction. Pupils

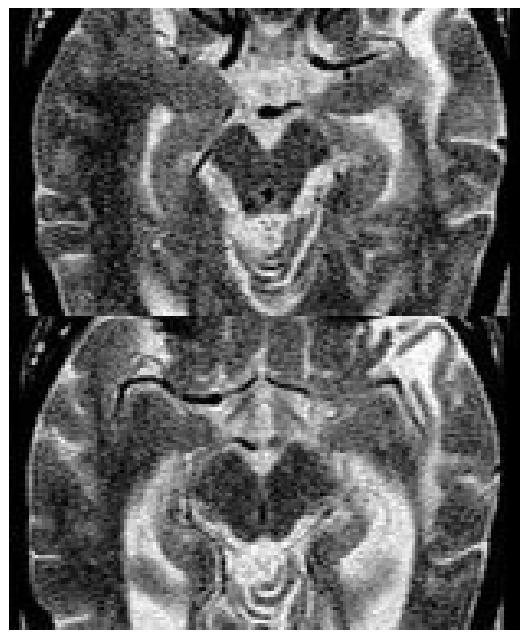

Figure 2 Case 1. T2 weighted (TR 3570, TE $120 \mathrm{~ms}$ ) spin echo sequences, $3 \mathrm{~mm}$ thickness, with normal findings in the mid-brain.

were equal in size and measured $5 \mathrm{~mm}$ in normal room light, with normal reactions. Cycloplegic refraction after instillation of two drops of $1 \%$ cyclopentolate and one drop of $1 \%$ tropicamide revealed $-1.25 \mathrm{sph}-1.50 \mathrm{cyl} \times 5$ right eye and $-0.75 \mathrm{sph}-1.25 \mathrm{cyl} \times 165 \mathrm{left}$ eye, obtaining 20/20 in each eye. She had attention and memory deficits, left cerebellar ataxia, left pyramidal syndrome, and speech difficulties due to vocal cord paresis. The MRI scan showed multiple lesions in the periventricular and subcortical white matter involving the left temporal lobe (Fig 1) and in the frontal and parieto-occipital regions bilaterally on FLAIR sequences. High signal intensity was observed in the cerebellar vermis as well as in the dorsal pons (Fig 1). No abnormalities was observed in the mid-brain Images with $3 \mathrm{~mm}$ thickness $\mathrm{T} 2$ weighted spin echo sequences also did not reveal abnormalities in the mid-brain (Fig 2).

The cycloplegic refraction was prescribed but she returned 2 months later complaining of blurred vision. She was prescribed -2.50 $\mathrm{sph}-1.50 \mathrm{cyl} \times 5$ right eye and $-2.00 \mathrm{sph}-1.25$

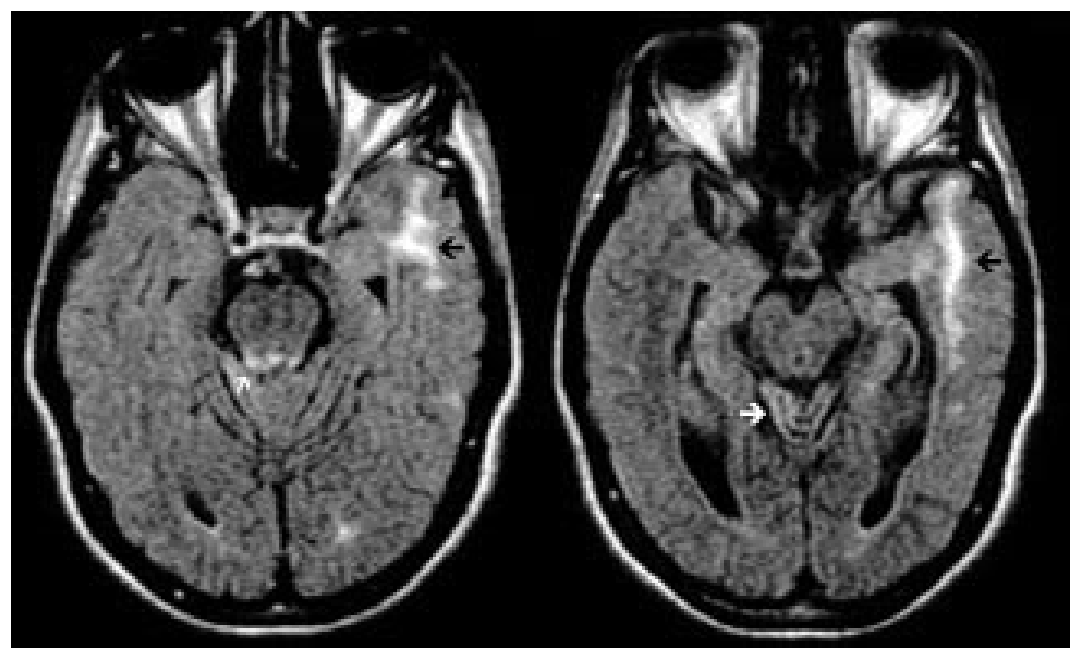

Figure 1 Case 1. Magnetic resonance imaging FLAIR sequences (TR 8000, TE 150, TI $2300 \mathrm{~ms}$ ) magnetic resonance imaging scan (6 mm thickness) showing white matter lesion in the temporal lobe (black arrows), in the dorsal pons (small white arrow), and in the cerebellar vermis (large white arrow). Cerebellar atrophy is indicated by enlarged folia. cyl $\times 165$ left eye which she has been wearing for 6 years, despite still having difficulties with distance vision. Multiple repeat examinations confirm that she needs -1.25 sph over her glasses in order to reach $20 / 20$ vision in each eye. Cycloplegic refraction remain unchanged from the first examination.

\section{Case 2}

A 24 year old male patient had blurred distant vision soon after he recovered from head injury including a 2 months period in a coma. He had not worn glasses in the past.

On examination visual acuity was 20/200 both eyes without correction and 20/25 with $-3.00 \mathrm{sph}$ in each eye. Pupils measured $4 \mathrm{~mm}$ each with normal reactions. The rest of the ophthalmic examination was normal. $\mathrm{Cy}-$ cloplegic refraction, after instillation of two drops of $1 \%$ cyclopentolate and one drop of $1 \%$ tropicamide, revealed 20/20 vision both eyes (+0.25 sph in each eye). He had recent memory and gait deficits. MRI scan revealed a heterogeneous area, hypointense on $\mathrm{Tl}$ and hyperintense on T2 weighted images, affecting the left temporal lobe, compatible with gliotic reaction. There were no abnormalities in the dorsal mid-brain.

The patient was prescribed $1 \%$ atropine every 12 hours, which he took for 6 months with normal distance vision but he complained of difficulties reading and photophobia. Atropine was discontinued and blurred distant vision recurred. He then took atropine every other day for 2.5 years associated with reading glasses. When it was discontinued however, accommodative spasm again recurred and a -3.00 sph correction in both eyes was prescribed.

\section{Comment}

In our patients, a relation of accommodative spasm and the head trauma seems well established because it appeared soon after they have recovered from severe head injury, persisted for several years despite the prolonged use of cycloplegic drops, and the patients were not trying to obtain any benefit by complaining of blurred vision.

The supranuclear control of accommodation is poorly understood. In cats, neurons that discharge in temporal correlation with accommodation were found in the lateral suprasylvian area. ${ }^{3}$ Electrical stimulation on ipsilateral interpositus nuclei and on contralateral interpositus and fastigial nuclei in the cerebellum are known to induce accommodation. ${ }^{4}$ These nuclei are connected to parasympathetic oculomotor neurons in the midbrain. $^{3}$

Very little accommodative dysfunction resulting from central lesions has been reported in humans. Ohtsuka et al studied a patient with left middle cerebral artery occlusion who had reduced accommodative responses and markedly lowered accommodation velocity. Their patient had low density lesions on computed tomograph (CT) scan involving the left temporal lobe, near the sylvian fissure. Kawasaki et al ${ }^{6}$ reported a patient with normal accommodation amplitude but increased accommodation and relaxation times. Their patient recovered normal accommodation 10 days after removal of a large subtentorial arachnoid cyst and the authors suggested that the cerebellum might have a role in the organisation of the human central control system of accommodation.

Bohlmann and France described a patient with persistent spasm of accommodation after head trauma. ${ }^{2}$ CT scan revealed a skull base fracture without intracranial abnormalities and the authors suggested that a possible 
mesencephalic lesion might be responsible for the spasm. Chan and Trobe ${ }^{7}$ reported a retrospective review of six patients with posttraumatic pseudomyopia but did not include MRI studies. In our patients, MRI scan failed to show abnormalities in the mid-brain. Both of them had lesions in the left temporal lobe and the first patient also had abnormalities in the frontal and parieto-occipital lobes bilaterally and the cerebellum. Although it is possible that they have small mesencephalic lesions, not detected by MRI scan, the findings is our cases suggest a higher origin for accommodative dysfunction in some patients with closed head trauma.

M L R Monteiro

Department of Ophthalmology, Hospital das Clínicas of the University of São Paulo Medical School, São Paulo, Brazil

A L L Curi

Department of Ophthalmology, Fluminense Federal University, Niterói, Rio de Janeiro, Brazil

A Pereira

Department of Ophthalmology, Hospital das Clínicas of the University of São Paulo Medical School, São Paulo, Brazil

W Chamon

Department of Ophthalmology, São Paulo Federa University, São Paulo, Brazil

C C Leite

Department of Radiology, Hospital das Clínicas of the University of São Paulo Medical School, São Paulo, Brazil

Correspondence to: Mário L R Monteiro, MD, Av Angélica 1757 conj.61, 01227-200, São Paulo, SP,Brazil; mlrmonteiro@ terra.com.br

Accepted for publication 18 July 2002

\section{References}

1 Goldstein JH, Schneekloth BB. Spasm of the near reflex: a spectrum of anomalies. Surv Ophthalmol 1996;40:269-78.

2 Bohlmann BJ, France TD. Persistent accommodative spasm nine years after head trauma. J Clin Neuro-ophthalmol 1987; 7: 129-34.

3 Bando T, Yamamoto N, Tsukahara N. Cortical neurons related to lens accommodation in posterior lateral suprasylvian area in cats. J Neurophysiol 1984;52:879-91.

4 Hosoba M, Bando T, Tsukahara N. The cerebellar control of accommodation of the eye in the cat. Brain Res 1978;153:495-505

5 Ohthsuka K, Maekawa H, Takeda M, et al. Accommodation and convergence insufficiency with left middle cerebral artery occlusion. Am J Ophthalmol 1988;106:60-4.

6 Kawasaki T, Kiyosawa M, Fujino T, et al. Slow accommodation release with a cerebellar lesion. Br J Ophthalmol 1993;77:678.

7 Chan RVP, Trobe JD. Spasm of accommodation associated with closed head trauma. J Neuro-Ophthalmol 2002;22:15-17.

\section{Extramedullary plasmacytoma of the eyelid}

A 74 year old man presented with a foreign body sensation in the right eye superimposed on a slowly growing enlarging lump in the right eyelid. He had no history of recurrent infections, bleeding, weight loss, or night sweats. His only other symptom was chronic backache secondary to osteoarthritis. Pas medical history included cataract extraction from the right eye 4 years previously and excision of a basal cell carcinoma from the right pinna 5 years previously. Examination

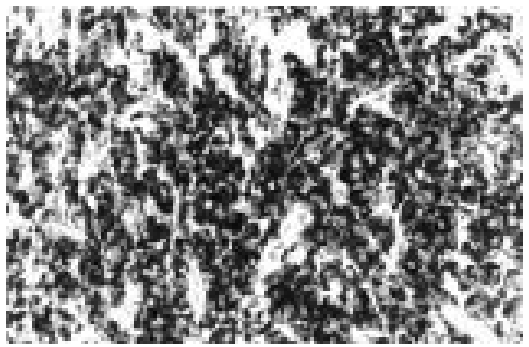

Figure 1 Photomicrograph showing infiltration of the conjunctiva by the neoplastic plasma cells with strong immunocytochemical staining for immunoglobulin $\lg G(\times 355)$.

revealed a large firm lesion in the right upper eyelid with no palpable lymph nodes. The clinical diagnosis was of a chalazion.

The lesion was removed surgically and histopathology (Fig 1) revealed an incompletely excised extramedullary plasmacytoma with a high proliferative index and amyloid change. Immunocytochemistry was positive for IgG kappa light chains. Further investigations including full blood count, liver function tests including lactate dehydrogenase (LDH), protein electrophoresis, skeletal survey, and bone marrow aspiration were normal with no evidence of multiple myeloma.

The whole of the upper eyelid was treated with radiotherapy using a customised lead cutout with internal shielding of the eye (Fig 2 ); $120 \mathrm{kV} x$ rays were used giving a dose of 30 Gy in 10 fractions over 2 weeks.

On follow up (at 2 years) there has been no evidence of local recurrence or the development of myeloma, and lacrimation in the eye appears normal.

\section{Comment}

Solitary plasmacytomas are rare tumours. They are classified as either solitary plasmacytomas of bone (SPB) or extramedullary plasmacytomas (EMP) of soft tissue. The majority of EMPs (about 80\%) involve the upper air passages of the head and are thought to arise in the submucosa, where plasma cells are numerous. ${ }^{34}$ Other sites include lymph nodes, spleen, skin and subcutaneous tissues, gastrointestinal tract, thyroid, and testes.

There is a relation between solitary plasmacytomas and subsequent development of multiple myeloma. About 44-69\% of patients with a solitary bone plasmacytoma will develop multiple myeloma within a median time of 3 years. ${ }^{5}$ Although EMPs recur in almost $50 \%$ of cases, this is usually in bone but unlike multiple myeloma it remains circumscribed within the bone with no predilection

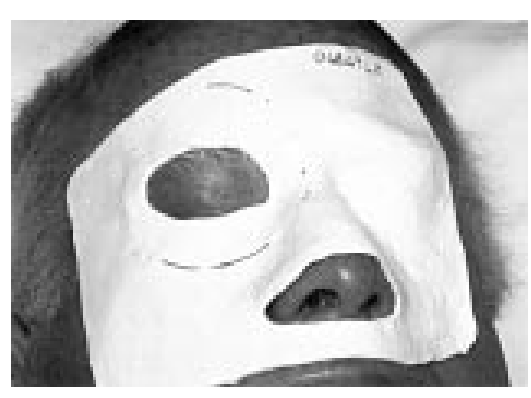

Figure 2 Whole of upper eyelid treated by radiotherapy using a customised lead cutout with internal shielding of the eye. for the axial skeleton. However, progression to myeloma does occur though at a lower rate than for SPB. Alexiou et al ${ }^{4}$ reported a rate of progression to myeloma for both upper aerodigestive tract and non-aerodigestive tract extramedullary soft tissue plasmacytomas of $16.1 \%$ and $14.6 \%$ respectively. As no predictors of progression have been identified patients probably need indefinite follow up.

Eye abnormalities such as cysts of the ciliary body and vascular lesions have been described in multiple myeloma but primary plasmacytoma involving the eye is rare. Nineteen cases affecting the orbit have been described in the literature but this is only the fourth case of a primary plasmacytoma arising from the eyelid that has been reported. Most of the earlier reports of the plasmacytomas arising in the eye are not true plasmacytomas and are in fact granulomas due to chronic inflammation. ${ }^{7}$ Usual symptoms are progressive painless swelling of the eyelid, proptosis, and diplopia. They can occur at any age but the mean age of onset is in the sixth to seventh decade. The youngest reported case was that of an 11 year old who had plasmacytoma of the orbit.

Of the three previously reported cases, all were treated with surgical excision. ${ }^{7910}$ Their immunocytochemistry was IgG lambda chain, kappa light chain, and IgG lambda chain respectively. Our case is similar but was treated successfully with radiotherapy after incomplete excision.

Solitary extramedullary plasmacytomas can be controlled with radiotherapy alone. Response rates with radiotherapy are as high as $94 \%$ and $93 \%$ for SPB and EMP respectively. ${ }^{11}$ The optimal dose of radiotherapy has not been defined, though it appears that a dose of at least $30 \mathrm{~Gy}$ is required. Many centres use doses of between 40-50 Gy. The extent of radiotherapy portals is also a subject of debate with many recommending inclusion of regional lymph nodes if possible. The median survival of patients with EMP treated with radiotherapy was 8.5 years in one study with most patients dying of causes unrelated to their EMP. ${ }^{12}$

Surgery is also an option, with Alexiou et $a l^{4}$ reporting a lower rate of progression to myeloma for those treated by surgery $(6.3 \%)$ compared with those treated with radiation $(17.5 \%)$. The conversion rate for patients treated with both modalities was $13.5 \%$. These results may reflect differences in the size of lesions, with small extramedullary plasmacytomas in easily accessible sites being amenable to surgical excision.

Chemotherapy is used for those patients who progress to multiple myeloma.

E Ahamed, L M Samuel, J E Tighe ANCHOR Unit, Aberdeen Royal Infirmary, Foresterhill, Aberdeen AB25 2ZN, UK

Correspondence to: Dr L M Samuel, ANCHOR Unit, Ward 17, Aberdeen Royal Infirmary, Foresterhill, Aberdeen AB25 2ZN, UK; L.Samuel@arh.grampian.scot.nhs.uk

Accepted for publication 22 July 2002

\section{References}

1 Woodruff RK, Whittle JM, Malpas JS. Solitary plasmacytoma. I Extramedullary soft tissue plasmocytoma. Cancer 1979:43:2340-3

2 Uceda-Montanes A, Blanco G, Saornil MA, et al. extramedullary plasmacytoma of the orbit. Acta Ophthalmol Scand 2000;78:601-3.

3 Selby P, Gore M. Myeloma and other plasma cell malignancies. Oxford Textbook of Oncology. Vol 2 .1995; 12:81852-78. 
4 Alexiou C, Kan RJ, Dietzfelbinger $\mathrm{H}$, et al. Extramedullary plasmacytoma. Cancer 1999;85:2305-14

5 Dimopoulos MA, Goldstein J, Fuller L, et al curability of solitary bone plasmacytoma. J Clin Oncol 1992:10:587-90.

6 Ganjoo RK, Malpas JS. Plasmacytoma, myeloma:biology and management. New York 1995;463-76.

7 Seddon JM, Corwin JM, Weiter JJ, et al Solitary extramedullary plasmacytoma of the palpebral conjunctiva. Br J Ophthalmol 1982;66:450-4

8 Sharma MC, Mahapatra AK, Gaikwad J, et al. Primary extramedullary orbital plasmacytoma in a child. Childs Nervous System 1996;1 2:470-2

9 Olivieri L, lanni $M D$, Giansanti $M$, et al. Primary eyelid plasmacytoma. Med Oncol 2000; 17:74-5

10 Choi WJ, Tchah H, Kim YJ. Plasmacytoma presented as a lid mass. Korean J Ophthalmo 1991;5:92-5.

11 Holland J, Trenkner DA, Wasserman TH, et al. Plasmacytoma-treatment results and conversion to myeloma. Cancer 1992;69:1513-17.

12 Knowling MA, Harwood AR, Bergsagel DE. Comparison of EMPs with solitary and multiple tumours of the bone. J Clin Oncol

$1983 ; 1: 255-62$

\section{Idiopathic sclerochoroidal calcification}

Sclerochoroidal calcification is a relatively rare condition characterised by yellow-white irregular subretinal lesions usually in the superotemporal mid-periphery of the fundus. It is usually asymptomatic and has a classic clinical appearance. Most cases are idiopathic but a few reports have associated this condition with abnormalities of electrolytes. ${ }^{1-5}$ We present three cases of idiopathic sclerochoroidal calcification.

\section{Case reports}

Case 1

A 71 year old white woman was referred by her optician after attending for routine glasses update. On questioning she did complain of a "slight blurring of vision" gradually for several months. She had a history of left amblyopia. Her medical history included asthma, osteoarthritis, lymphoedema, fibromyalgia, and hiatus hernia. Her only medications were inhalers and paracetamol. She had previously taken calcium supplements. Her visual acuities were $6 / 6$ in the right eye and $6 / 12$ in the left eye with a hypermetropic correction. She had early cortical lens opacities and no vitritis. Both fundi revealed minimally elevated yellow areas in the choroid along the superotemporal arcades (Fig lA).

The patient had haematological investigations revealing a normal full blood picture urea and electrolytes, ACE level, urate, liver function tests, bone profile, immunoglobulins, erythrocyte sedimentation rate (ESR), and $\mathrm{C}$ reactive protein. She also had a chest $x$ ray which was unremarkable. Her fundal photography showed autofluorescence of these lesions and ultrasound scanning aided the diagnosis in that the lesions were highly reflective with orbital shadowing (Fig 1B).

\section{Case 2}

An 82 year old white woman was referred by her optician complaining of a gradual reduction in vision bilaterally. She had recently been diagnosed with polymyalgia rheumatica and was well controlled with oral prednisolone. She had no headaches. Her medical history included oesophagitis and hiatus hernia and cervical spondylosis. Her unaided
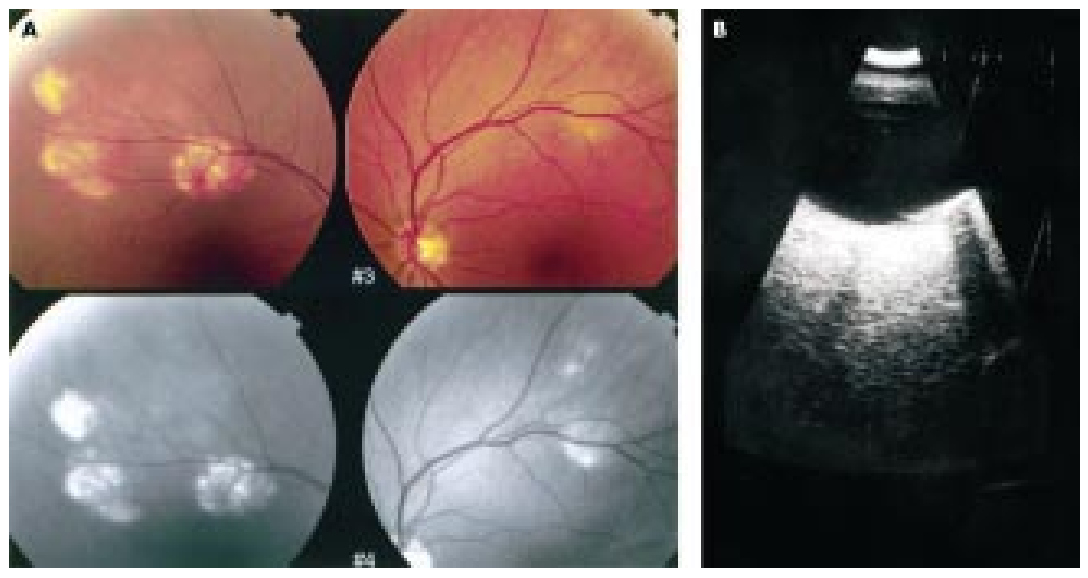

Figure 1 Case 1 (A) Elevated yellow areas along the supertemporal arcades bilaterally and demonstration of autofluorescence of these lesions. (B) Ultrasound scan showing the lesions to be highly reflective with orbital shadowing.

visual acuity was 6/12 right eye improving to 6/9 with pinhole, and 6/18 left eye improving to $6 / 12$ with pinhole. She had bilateral nucleosclerotic cataracts and both fundi revealed numerous pale elevated lesions clustered around the superotemporal and inferotemporal arcades (Fig 2A).

Haematological investigations and chest $x$ ray were unremarkable. Ultrasound scanning revealed that these were areas of calcification with high reflectivity (Fig 2B).

\section{Case 3}

A 71 year old man attended routinely for review 2 weeks after cataract extraction. He had no past medical history and vision was 6/9 right eye and 6/6 left eye. He was noted to have a small optic disc haemorrhage coincidentally and therefore dilated fundal examination was performed. He had bilateral pale
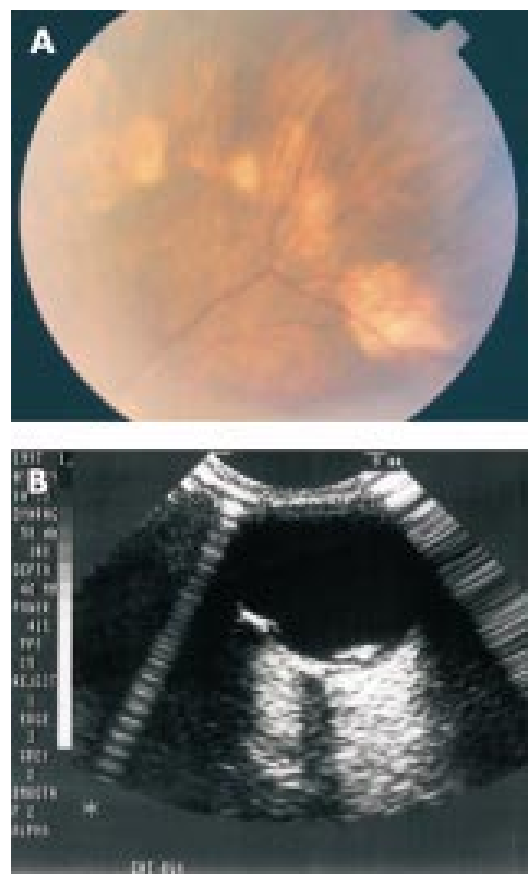

Figure 2 Case 2 (A) Pale yellow elevated lesions in the mid-periphery clustered around the superotemporal arcade. (B) Ultrasound of lesions revealing that they are areas of calcification with high reflectivity. yellow elevated lesions along the superotemporal arcades and also nasally in both fundi. Again electrolytes were investigated and were within the normal range.

\section{Comment}

Sclerochoroidal calcification has been described in the literature as an uncommon condition found usually in older white patients. ${ }^{3}$ Patients have been unnecessarily investigated in the past and even treated for tumours unnecessarily. ${ }^{4}$ Calcification can be dystrophic or metastatic but in these idiopathic cases it is the former. The calcification is believed to be deposited at the sites of insertions of the oblique extraocular muscles in a similar way that Cogan scleral plaques are calcification at the insertions of the horizontal recti muscles. ${ }^{5}$ Reports have been made of sclerochoroidal calcification associated with Bartter syndrome, ${ }^{1}$ Gitelman syndrome, ${ }^{2}$ hyperparathyroidism, and hypomagnesaemia. ${ }^{3}$ It is important to exclude any electrolyte abnormality when a patient presents with this condition, but prolonged investigations are unnecessary. Autofluorescence and ultrasound appearances are very useful to diagnose this condition. Patients rarely develop visual disturbance with sclerochoroidal calcification, but infrequent follow up is advised as cases of associated choroidal neovascular membranes and serous detachments with the lesions have been documented. ${ }^{6}$

\section{Acknowledgements}

ALCON kindly sponsored the publication costs of the figures.

C A Cooke, C McAvoy, R Best

Department of Ophthalmology, Royal Victoria Hospital, Belfast, Northern Ireland, UK

Correspondence to: Dr Carole A Cooke

Accepted for publication 29 July 2002

\section{References}

1 Marchini G, Tosi R, Parolini B, et al.

Choroidal calcification in Bartter syndrome. Am J Ophthalmol 1998;1 26:727-9

2 Bourcier T, Blain P, Massin P et al. Sclerochoroidal calcification associated with Gitelman syndrome. Am J Ophthalmol 1999;1 28:767-8.

3 Honavar SG, Shields CL, Demirci H, et al. Sclerochoroidal calcification. Arch Ophthalmol 2001;119:833-40.

4 Lim JI, Goldberg MF. Idiopathic

sclerochoroidal calcification. Arch Ophthalmol 1989;107:1122-3. 
5 Cogan DG, Kuwabara T. Focal senile translucency of the sclera. Arch Ophthalmol 1959; 62:604-10

6 Leys A, Stalmans P, Blanckaert J.

Sclerochoroidal calcification with choroidal neovascularization. Arch Ophthalmol 2000 118:854-7.

\section{Stereotactic irradiation of biopsy proved optic nerve sheath meningioma}

The role of conventional external beam radiotherapy in the management of optic nerve sheath meningiomas (ONSM) has been controversial because of limited radiation sensitivity of these tumours and radiation damage to surrounding tissues. ${ }^{1}$ Recently, in a study of 64 patients with ONSM managed with observation, surgery, radiotherapy, or surgery and radiotherapy, Turbin and colleagues ${ }^{2}$ found that patients treated by (conventional) radiotherapy alone demonstrated the best long term visual outcome, and suggested fraction ated external beam radiation (5000-5500 cGy) as the initial treatment in selected cases, when preservation of visual function is a reasonable goal.

The collateral damage secondary to conventional radiotherapy may be minimised by better focusing and shaping of the radiation beams, as in stereotactic radiotherapy (SRT). ${ }^{3-5}$ We report on a woman whom we treated with fractionated SRT for a biopsy proved, large ONSM.

In April 2000 a 41 year old woman was referred with a 1 month history of proptosis of her left eye (Fig 1, top left). She had been treated for a presumed orbital "pseudotu mour" with oral prednisone (initial dose 90 $\mathrm{mg}$ /day) without effect.

At referral, she had no history of diplopia or retrobulbar pain. On examination, the visua acuity (VA) was 1.25 (unaided) of the righ eye and $0.8+(\mathrm{cc} S+2)$ of the left eye. The intraocular pressure was 18 and $21 \mathrm{~mm} \mathrm{Hg}$ in the right eye and left eye, respectively. There was a left relative afferent pupillary defect (RAPD). The motility of the left eye was slightly restricted in upgaze. The left eye showed mild periocular swelling and conjunctival chemosis. There was $5 \mathrm{~mm}$ of left proptosis without upper eyelid retraction or lid lag. Funduscopy of both eyes showed no abnormalities. Visual field testing (Humphrey field analysis (HFA II 750) showed relative scotomas of the left eye, mainly in both lower quadrants. Visual evoked potential (VEP examination of the left eye showed prolonged latency and decreased amplitudes, suggestive of optic nerve dysfunction.

Orbital MRI (Tl weighted) scans showed a proptosis of the left eye and a large retrobulbar, intraconal mass that stained intensely with gadolineum contrast (Fig 1, bottom left). Computed tomography (CT) imaging also showed an intensely staining retrobulbar tumour with out calcifications, that encased and slightly displaced the optic nerve. There was no "tram tracking" sign or bone involvement. No tumour extension into the optic canal or intracranially was noted. Orbital colour Doppler ultrasound imaging showed a highly vascularised retrobulbar mass with a vertical diameter of at least $25 \mathrm{~mm}$ (Fig 2, top left).

Since, on imaging, no evident diagnosis could be made, we decided to perform a biopsy on the lesion through a lateral orbitotomy. At surgery, the tumour was pale and solid. Histopathological examination of the incisional biopsy specimen showed whorls of meningothelial cells, with small nuclei and
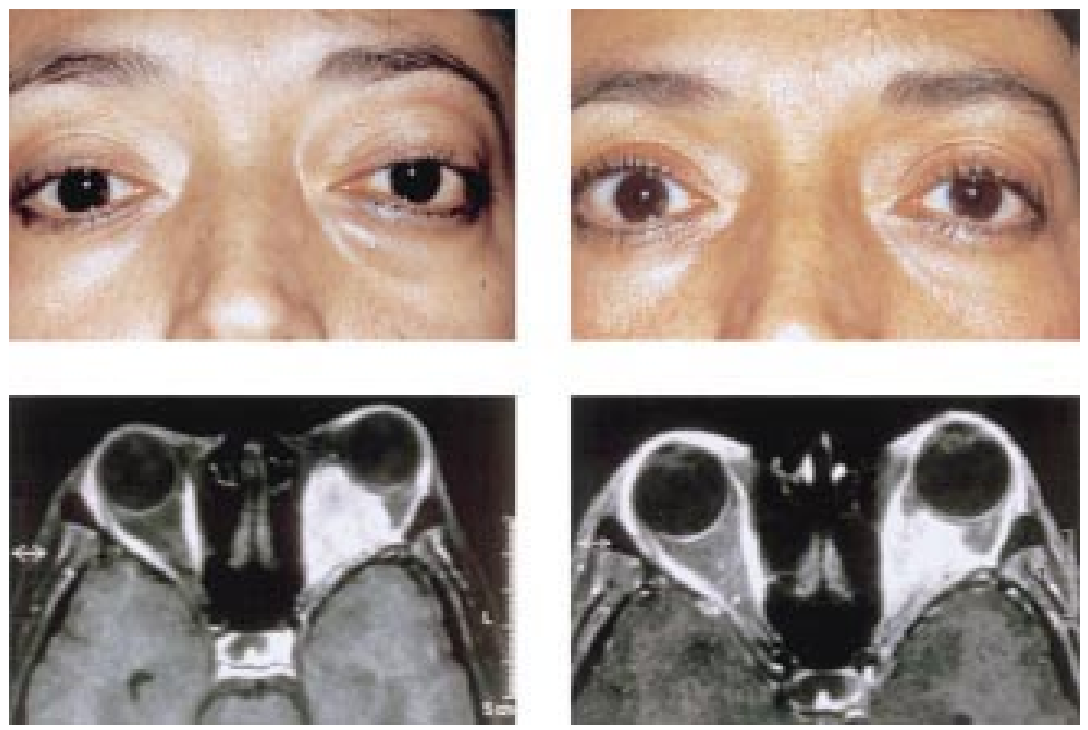

Figure 1 Top left. Appearance of a 41 year old woman with a biopsy proved optic nerve sheath meningioma before SRT. Note the left exophthalmos and periocular swelling. Top right Post-treatment appearance. Note the decrease of the fullness of the left eyelids. Also note the right upper lid retraction secondary to left upper lid ptosis. Bottom left. Orbital MRI scan (T1 weighted with fat suppression and gadolinium contrast enhancement) at presentation. Bottom right. Six months after radiotherapy. A decrease of both tumour size and proptosis is clearly visible.

inconspicuous nucleoli, consistent with a meningioma (Fig 2, bottom)

After surgery we observed the patient for 9 months. During this period her left (corrected) VA deteriorated to 0.2 and her left visual field showed progression of her scotomas. This prompted us to treat her with fractionated SRT in March 2001. The radiation, delivered with a $6 \mathrm{MV}$ linear accelerator (Varian), was given 5 days a week at 1.8 Gy per fraction, with a cumulative dose of $54 \mathrm{~Gy}$. Treatment planning was based on orbital MRI matched with CT scans. A non-invasive stereotactic frame was fixed with an external coordinate system (one isocentre). Target and sur-
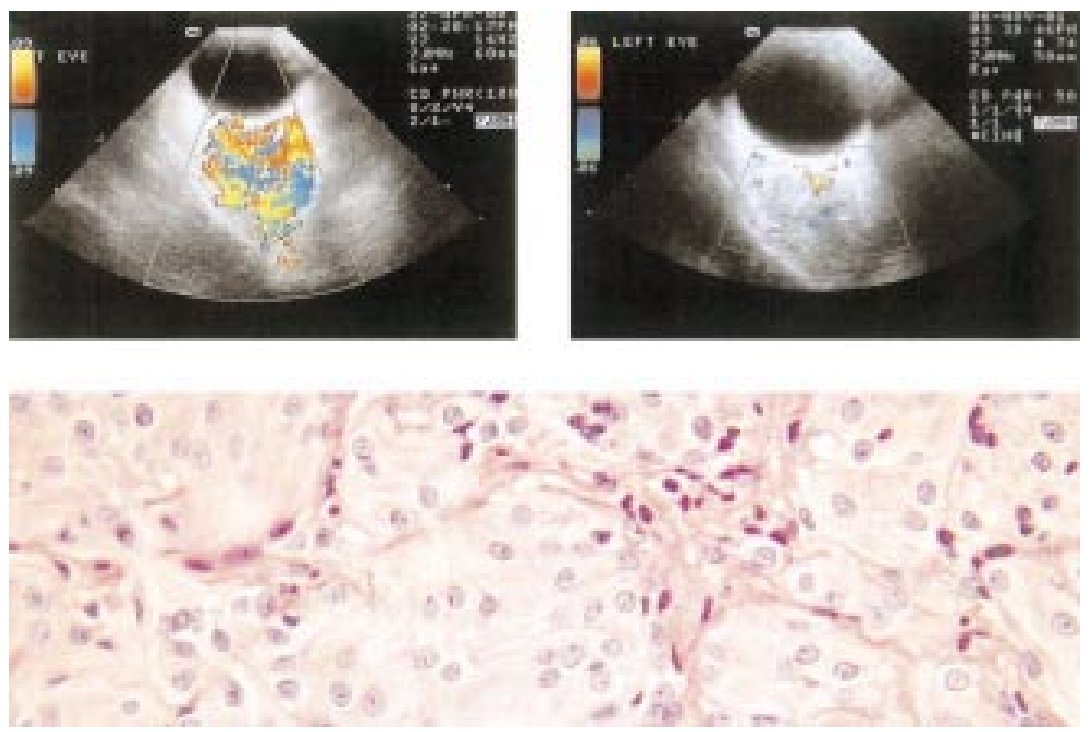

Figure 2 Top left. Ultrasound examination at presentation. A large, heavily vascularised retrobulbar mass is visible. Top right. Six months after radiotherapy, the tumour has diminished in size and vascularisation. Note that a different depth setting of the ultrasound system has been used. Bottom. Histopathology of the optic nerve tumour, showing whorls of meningothelial cells, with small nuclei and inconspicuous nucleoli (haematoxylin and eosin, $\times 200$ original magnification). 
Her periocular swelling had markedly diminished (Fig 1, top right). Compared to previous measurements, the protrusion of the left eye had diminished by $4 \mathrm{~mm}$. Funduscopy, however, showed mild pallor of the left optic nerve head. Visual field testing showed unchanged loss of the left visual field compared to pretreatment values, with a higher foveal threshold. VEP measurements showed improved amplitudes, but prolonged latency compared to previous examination. Orthoptic examination showed ductions similar to those before treatment. Post-treatment MRI revealed a markedly decreased tumour size and a decrease of exophthalmos (Fig 1, bottom right). Colour Doppler ultrasonography showed a decrease in tumour size with markedly diminished vascularisation (Fig 2, top right). At the last follow up visit, 16 months after treatment, her left VA and visual fields were stable.

\section{Comment}

As in the recent report on a presumed ONSM by Moyer et al, ${ }^{5}$ fractionated SRT in our biopsy proved case gave a remarkable visual recovery without detectable side effects. Both the size and the blood flow of the tumour regressed within the first 6 months, leading to reduced exophthalmos and periocular swelling. The effect of restored cosmesis was important to this young woman whose main complaint was her unilateral exophthalmos.

Since our follow up is limited to 16 months, no conclusions with regard to long term outcome can be made. More cases of SRT for ONSM need to be studied over a longer period of time to assess the efficacy of this treatment.

\section{Acknowledgements}

This study was presented in part at the 196th Annual Meeting of the Dutch Society of Ophthalmologists, Groningen, the Netherlands, March 2002.

The SWOO foundation is kindly acknowledged for financial support.

A D A Paridaens, R L J van Ruyven Rotterdam Eye Hospital, Oculoplastic Service

W M H Eijkenboom Erasmus Medical Centre Rotterdam, Department of Radiotherapy

CM Mooy

Erasmus University Rotterdam, Department of Ophthalmopathology

WA van den Bosch

Rotterdam Eye Hospital, Oculoplastic Service

Correspondence to: A D A Paridaens, MD PhD, The Rotterdam Eye Hospital, Oculoplastic Service, Schiedamsevest 180, 3011 BH Rotterdam, Netherlands; paridaens@ned.ne

Accepted for publication 25 July 2002

\section{References}

1 Dutton JJ. Optic nerve sheath meningiomas. Surv Ophthalmol 1992;37:167-83.

2 Turbin RE, Thompson CR, Kennerdell JS, et al. A long-term visual outcome comparison in patients with optic nerve sheath meningioma managed with observation, surgery, radiotherapy, or surgery and radiotherapy. Ophthalmology 2002; 109:890-900

3 Eng TY, Albright NW, Kuwahara G, et al. Precision radiation therapy for optic nerve sheath meningiomas. Int J Radiat Oncol Biol Phys 1992;22:1093-8.

4 Lee AG, Woo SY, Miller NR, et al. Improvement in visual function in an eye with a presumed optic nerve sheath meningioma after treatment with three-dimensional conformal radiation therapy. $J$

Neuro-ophthalmol 1996;16:247-51.
5 Moyer PD, Golnik KC, Breneman J. Treatment of optic nerve sheath meningioma with three-dimensional conformal radiation. Am J Ophthalmol 2000;129:694-6.

\section{Severe interferon associated retinopathy}

Interferon alfa is used in various human malignancies for its antitumour activity. One of its ocular side effects is retinopathy. ${ }^{1}$ Interferon associated retinopathy is generally mild and resolves completely. We describe a severe retinopathy in a hypertensive patient treated with interferon for multiple myeloma.

\section{Case report}

A 56 year old man presented with a 3 week history of deterioration and distortion of right vision. Visual acuities (VA) were 6/60 right and 1/60 left. Funduscopy revealed bilatera extensive peripapillary cotton wool spots, retinal thickening, optic disc hyperaemia, and blot haemorrhages. Arteriolar changes were minimal

He was anaemic (Hb $10.6 \mathrm{gdl} / \mathrm{l}$ ) and slightly thrombocytopenic (platelets $93 \times 10^{9} / 1$ ). Plasma viscosity was 1.59 (normal 1.5-1.7). Renal function was normal at presentation.

He underwent peripheral blood stem cell transplant for multiple myeloma 8 months previously after having melphalan $110 \mathrm{mg} / \mathrm{m}^{2}$ and total body irradiation (including the head) in a total dose of 1200 cGy given in six fractions over 3 days. He then had interferon alfa therapy for 4 months, initially 3 mega units three times a week, later reduced to twice a week. It was stopped immediately after visual deterioration.

Five years previously, he had macular laser treatment following left inferotemporal branch retinal vein occlusion. On discharge 1 year later, VAs were right 6/5, left 6/36.

He was a known hypertensive, taking lisinopril, but control was poor around the

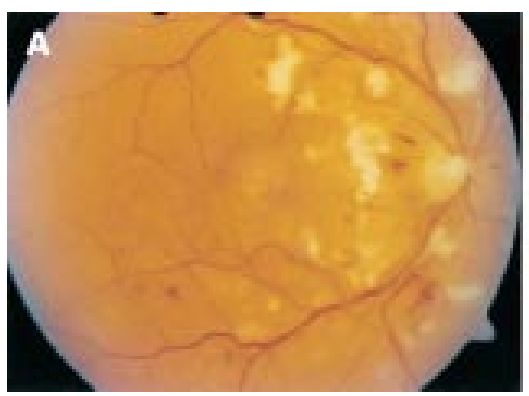

Figure 1 Bilateral (right eye (A) and left eye (B)) extensive peripapillary cotton wool spots, retinal thickening with exudates, optic disc hyperaemia, and blot haemorrhages.
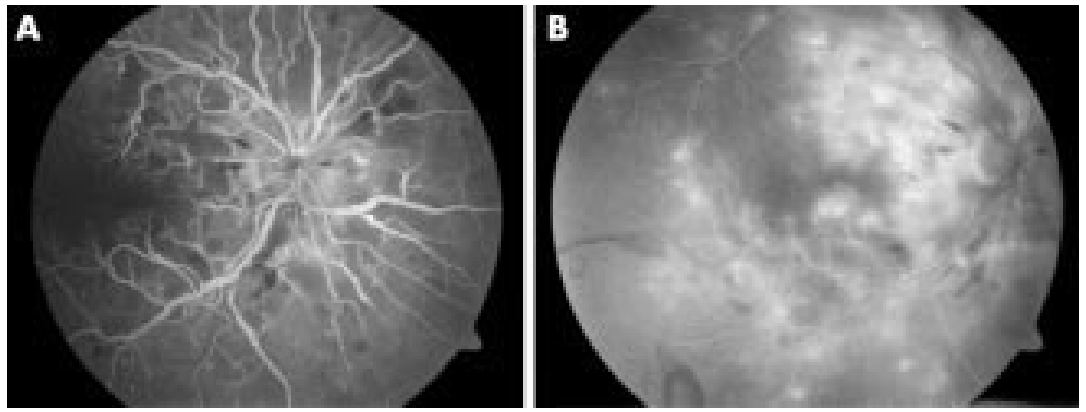

Figure 2 Fundus fluorescein angiography of the right eye: early frame (A) showing retinal ischaemia with capillary non-perfusion, pruning, and tortuosity of vessels; late frame (B) showing vessel wall staining and leakage. pathy was noted and subsequent proliferative

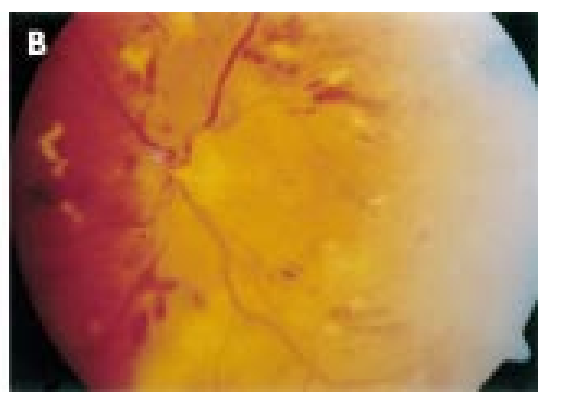

time his VA began to deteriorate, with readings up to $150 / 100 \mathrm{~mm} \mathrm{Hg}$. He was not diabetic His myeloma status was stable. Cytomegalovirus (CMV) antigen checked by polymerase chain reaction (PCR) and preransplant HIV status were negative.

One week after presentation at the eye clinic, VAs dropped to right $2 / 60$, left finger counting and did not improve after a course of . spots and haemorrhages were more merous and both foveas showed gross fluorescein angiography revealed retinal ischaemia with capillary non-perfusion, pruning, and tortuosity of vessels, vessel wall staining, and leakage (Fig 2).

Five months later preproliferative retinowere treated with bilateral panretinal laser photocoagulation. At 9 months, VAs

\section{Comment}

In a review article on interferon retinopathy, nitial interferon alfa doses ranged from -9 mega units three to six times per randomised placebo controlled trial of interferon alfa therapy for macular degeneration, retinopathy was noted with ncreasing frequency in the highest dose group ( $5 \%$ of the patients taking 6 mega units three times a week). ${ }^{2}$ The interferon doses in our patient were at the lower level of these regimens.

to of retinopathy was found to be Se the prence of the fowing risk treatment, and systemic diseases like diabetes mellitus or hypertension. Early onset of retinopathy was also a good indicator of severity 
and fundal examination up to 8 weeks from start of treatment was advocated for those at risk. $^{3}$

Significant visual impairment attributed to interferon therapy was associated with macular oedema in a hypoalbuminaemic but non-hypertensive, non-diabetic patient ${ }^{4}$; and in two other cases in a case series report, one of whom had poor control of blood pressure and the other an occasional mildly elevated blood glucose level. ${ }^{5}$ All three patients had resolution of the lesions by 2 months and subsequently made good visual recoveries, unlike in our case.

In another case series report, two out of seven patients on high dose interferon alfa-2b suffered permanent visual loss after developing macular oedema. Both patients were hypertensive and one had radiation treatmen to the brain. The latter later developed proliferative retinopathy as well.

Deposition of immune complexes in the retinal vasculature has been postulated as a pathogenetic mechanism for the retinopathy. Interferon alfa was also found to induce leucocyte capillary trapping in rat retinal microcirculation.

Radiation may have contributed to the development of the clinical picture although its use in the treatment of myeloma is frequent and ocular side effects have not been widely recognised in the past. Low doses to the eye similar to that used in our patien have been associated with retinopathy after treatment of age related macular degeneration.

Retinal oedema is an indicator of severity in interferon associated retinopathy. Early detection of it, especially in hypertensives and dia betics, may help avoid progression to permanent visual loss.

\section{K L Tu, J Bowyer, K Schofield, S Harding}

Correspondence to: Mr K L Tu, St Paul's Eye Unit Royal Liverpool University Hospital, Liverpoo L7 8XP, UK; kltu@ntlworld.com

Accepted for publication 29 July 2002

\section{References}

1 Hayasaka S, Nagaki $Y$, Matsumoto $M$, et al Interferon associated retinopathy. $\mathrm{Br}$ Ophthalmol 1998;82:323-5.

2 Pharmacological Therapy for Macular Degeneration Study Group. Interferon alfa-2a is ineffective for patients with choroidal neovascularization secondary to age-related macular degeneration. Arch Ophthalmol 1997;115:865-72.

3 Soushi S, Kobayashi F, Obazawa H, et al. Evaluation of risk factors of interferon-associated retinopathy in patients with type $\mathrm{C}$ chronic active hepatitis. Nippon Ganka Gakkai Zasshi 1996;100:69-76. (English extract)

4 Tokai R, Ikeda T, Miyaura T, et al. Interferon-associated retinopathy and cystoid macular edema. Arch Ophthalmol 2001;119:1077-9

5 Guyer DR, Tiedeman J, Yannuzzi LA, et al. Interferon associated retinopathy. Arch Ophthalmol 1993;111:350-6.

6 Heniy C, Sternberg P Jr, Lawson DH, et al. Retinopathy associated with high-dose interferon alfa-2b therapy. Am J Ophthalmol $2001 ; 131: 782-7$.

7 Nishiwaki H, Ogura Y, Miyamoto K, et al. Interferon alfa induces leukocyte capillary trapping in rat retinal microcirculation. Arch Ophthalmol 1996;114:726-30.

8 Mauget-Faysse M, Chiquet C, Milea D, et al. Long term results of radiotherapy for subfoveal choroidal neovascularization in age related macular degeneration. $\mathrm{Br} J$ Ophthalmol 1999;83:923-8.

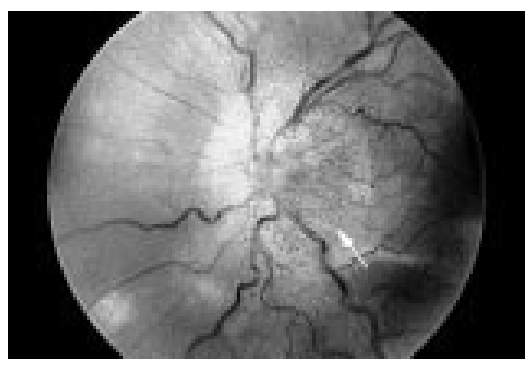

Figure 1 Fundus photograph of the left optic disc shows diffuse swelling and increased surface vascularity. Additionally, a more focal elevation at the inferotemporal quadrant gives a nodule-like appearance to the disc swelling (arrow). The irregular white spot at the lower left corner of the figure is a photographic artefact.

\section{Mass lesions of the posterior segment associated with Bartonella henselae}

Bartonella (previously Rochalimea) henselae is the infectious agent causing cat scratch disease, a self limited regional lymphadenopathy associated with flu-like symptoms. ${ }^{1}$ In approximately $10 \%$ of cases, extranodal dissemination of the organism results in a variety of intraocular inflammatory lesions. ${ }^{1}$ We report a patient with acute Bartonella henselae infection in whom the only physical manifestation was multiple, mass-like lesions in the eye which resembled ocular metastases.

\section{Case report}

A 12 year old boy developed daily headaches and blurred vision. Four weeks later, he noted a central grey spot in his left eye. Visual acuity was 20/20 in his right eye and 20/400 left eye. Goldmann perimetry of the left eye revealed a dense central scotoma with steep margins nasally and moderate constriction of the temporal periphery. An afferent pupillary defect was present on the left side. Slit lamp examination was normal in both eyes. Funduscopy of the left eye showed nodular optic disc swelling with peripapillary subretinal elevation (Fig l). A large creamy-coloured mass (approximately one and one half disc diameter) withou exudates or haemorrhages was present in the macula. Several smaller but similar, elevated lesions of the choroid were detected in the periphery as well as an inferior serous retina detachment. There was no evidence of ocular inflammation. An orbital ultrasound showed the macular lesion to be a solid mass without associated subretinal fluid (Fig 2).

Complete blood count, electrolytes, and glucose were normal. A sedimentation rate

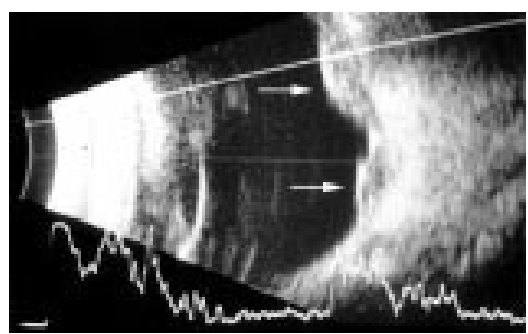

Figure 2 Orbital ultrasound at the macula of the left eye demonstrates a focal area of elevation and high reflectivity consistent with a solid mass lesion (arrows). was marginal at $18 \mathrm{~mm} /$ hour (normal less than $15 \mathrm{~mm} /$ hour). Antinuclear antibodies were elevated at 1:320, speckled pattern. Rheumatoid factor was negative. Evaluation for various infectious aetiologies was negative, including Bartonella serologies (IgM and IgG). A systemic evaluation for a primary tumour causing possible ocular metastases was negative. The patient was empirically treated with doxycycline $100 \mathrm{mg}$ twice daily for 10 days. The macular mass and choroidal lesions resolved in 4 weeks. Shortly thereafter, the disc swelling resolved. Because a diagnosis remained lacking, serologies were repeated $\mathrm{l}$ month later and revealed a marked rise of Bartonella titres, confirming a recent $B$ henselae infection ( $B$ henselae $\operatorname{IgM}=24$, normal less than 16, and $B$ henselae IgG $=1024$, normal less than 256). Final visual acuity was 20/70 left eye due to residual peripapillary and macular gliosis.

\section{Comment}

The range of ocular findings associated with $B$ henselae continues to expand. The classic follicular conjunctivitis described with lymphadenopathy and fever (Parinaud's ocular glandular syndrome) is due to direct inoculation of the conjunctiva. Neuroretinitis, a syndrome of acute visual loss associated with optic disc swelling and macular star, was the first established intraocular complication from disseminated Bartonella. ${ }^{3}$ Since then, other reported intraocular findings include inflammatory chorioretinal white spots, papillitis, serous detachment, vitritis, uveitis, vasculitis, retinal vaso-occlusive disease, and vitreous haemorrhage. ${ }^{1-4} \mathrm{~A}$ mass lesion at the optic nerve head has been noted in several instances. ${ }^{45}$ A solitary macular lesion without other ocular inflammatory findings has also been reported. ${ }^{6}$ Such lesions in the posterior pole have been presumed to represent a massive focus of Bartonella inflammation.

We report a patient with a circumscribed, elevated lesion in the macula as well as other mass-like lesions at the optic nerve head and in the choroid. These lesions occurred in the absence of systemic or ocular inflammation and clinically resembled ocular metastases. This case highlights the importance of recognising the wide spectrum of ocular bartonellosis. Furthermore, clinicians are reminded that cat exposure is not essential for contracting the bacteria and, therefore, Bartonella titres should be obtained whenever there is a clinical index of suspicion, regardless of cat exposure.

A Kawasaki

Department of Neuro-ophthalmology, University Eye Clinic of Lausanne, Hopital Ophtalmique, Jules Gonin, Lausanne, Switzerland

D L Wilson

Departnment of Ophthalmology, Indiana University Medical Center and Midwest Eye Institute, Indiana University and Clarian Hospitals of Indiana, Indianapolis, IN, USA

Correspondence to: Aki Kawasaki, MD, Hopital Ophtalmique Jules Gonin, Department of Neuro-ophthalmology, Ave de France 15, CH 1004 Lausanne, Switzerland; aki.kawasaki@ophtal.vd.ch

Accepted for publication 9 August 2002

\section{References}

1 Cunningham ET Jr, Koehler JE. Ocular bartonellosis. Am J Ophthalmol 2000;130: 340-9.

2 Ormerod LD, Skolnick KA, Menosky MM, et al. Retinal and choroidal manifestations of cat-scratch disease. Ophthalmology 1998;105:1024-31. 
3 Golnik KC, Marotto ME, Fanous MM. Ophthalmic manifestations of Rochalimaea species. Am J Ophthalmol 1994;1 18:145-51.

4 Solley WA, Martin DF, Newman NJ, et al.

Cat scratch disease. Posterior segment manifestations. Ophthalmology

1999; 106:1546-53

5 Cunningham ET Jr, McDonald HR, Schatz $\mathrm{H}$, et al. Inflammatory mass of the optic nerve head associated with systemic Bartonella henselae infection. Arch Ophthalmol 1997; 115:1596-7.

6 Pollock SC, Kristinsson J. Cat-scratch disease manifesting as unifocal helioid choroiditis. Arch Ophthalmol 1998;116:1249-51.

\section{Optic neuritis with marked distension of the optic nerve sheath due to local fluid congestion}

Distension of the subarachnoid space of the optic nerve is not a common feature of optic neuritis. We describe a patient with optic neuritis with swelling of the optic nerve head of the right eye. On magnetic resonance imaging (MRI) there was marked distension of the optic nerve sheath due to an increase of fluid in the subarachnoid space. The location of the lesion in the optic nerve and concurrent inflammatory changes of the arachnoid trabecula and septae may have had a role in the pathophysiology of this condition.

\section{Case report}

A 38 year old man was admitted with pain on eye movements and loss of vision in the right eye. Best corrected visual acuities measured $20 / 40$ on the right and $20 / 20$ on the left. The patient identified 16 out of 18 Ishihara plates with the right eye and 18/18 with the left eye. There was a relative afferent pupillary defici (RAPD) on the right. Funduscopy demon strated a swollen optic disc on the right. The left optic disc was normal. Spontaneous venous pulsations (SVP) were detectable bilaterally. Laboratory examinations, including red and white blood counts, $\mathrm{C}$ reactive protein, sedimentation rate, serologies for syphilis, HIV, herpes, toxoplasmosis, Lyme disease and cytomegalovirus, as well as colla gen vascular disorders and coagulopathies were all in normal range. The right visual field (Octopus program G2) demonstrated a wedge-shaped defect in the inferior nasal and temporal visual field pointing towards the macula. The left visual field was normal. Neurological examination was normal. MR of the brain was normal but showed enhancement of the right optic nerve in the Tl weighted axial and coronal (not shown) image and hyperintense fluid in the expanded optic nerve sheath on the T-2 weighted image (Fig lA and B). Two days after admission the visual acuity in the right eye decreased to 20/100 and only two out of 18 Ishihara plates were identified. SVP were no longer present on the right. The swelling of the right optic disc progressed and temporal peripapillary Patton folds appeared, suggesting the diagnosis of papilloedema (Fig 2). Within 2 weeks visual acuity improved to 20/25 right eye and colour vision returned to normal. A repeat MRI of the orbits 7 weeks later demonstrated normal diameters of both perioptic subarachnoid spaces (Fig lC).

\section{Comment}

Distension of the perioptic subarachnoid space is a hallmark MRI feature of papilloedema due to an intracranial mass lesion, inflammatory disease, and pseudotumour cerebri. ${ }^{1}$ Unilateral distension of the of the
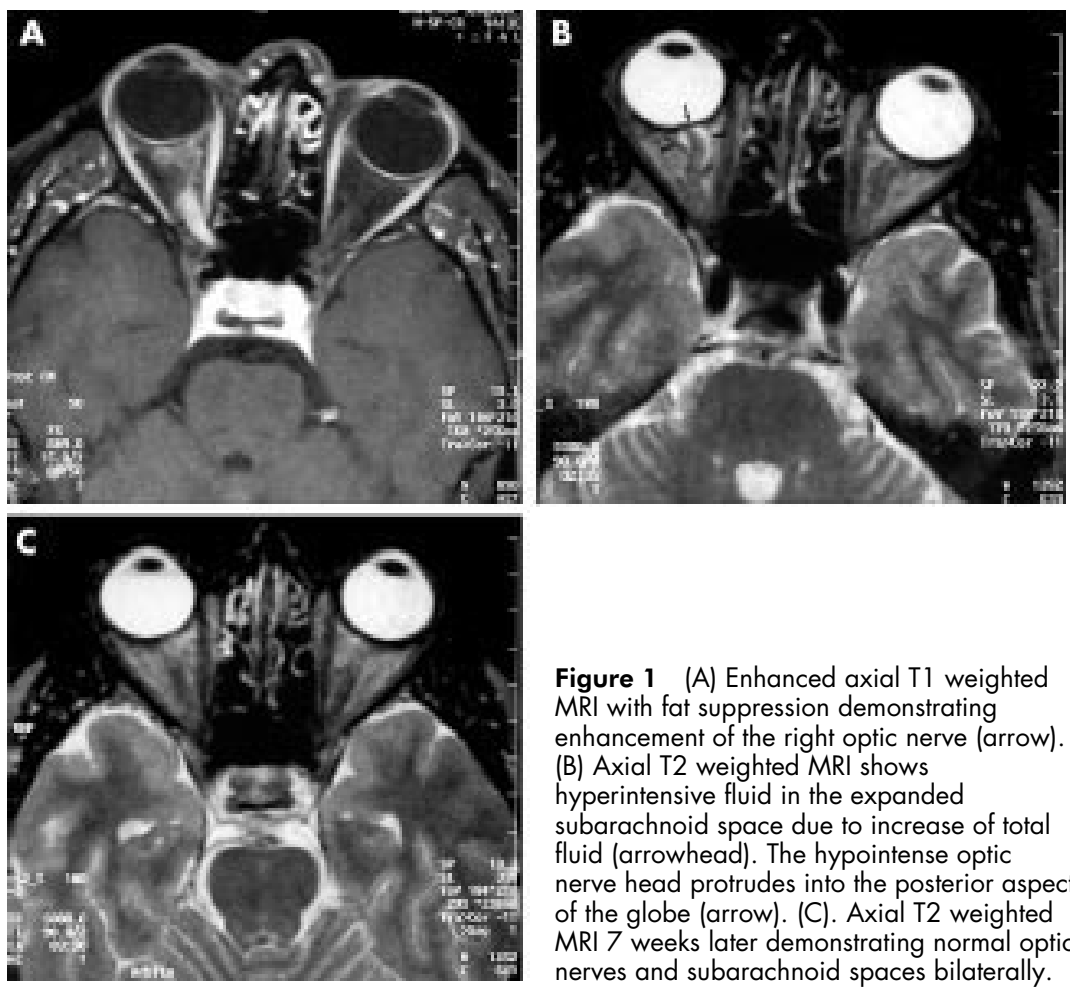

Figure 1 (A) Enhanced axial T1 weighted MRI with fat suppression demonstrating enhancement of the right optic nerve (arrow). (B) Axial T2 weighted MRI shows hyperintensive fluid in the expanded subarachnoid space due to increase of total fluid (arrowhead). The hypointense optic nerve head protrudes into the posterior aspect of the globe (arrow). (C). Axial T2 weighted MRI 7 weeks later demonstrating normal optic nerves and subarachnoid spaces bilaterally.

optic nerve sheath due to increased fluid volume of the subarachnoid space of the optic nerve has previously been reported in some patients with optic hydrops, anterior ischaemic optic neuropathy, and anatomical anomalies such as arachnoid cysts. ${ }^{2-4}$ This patient with optic neuritis demonstrated marked distension of the subarachnoid space of the right optic nerve, presumed to be caused by an increase of total fluid following optic neuritis. As all cerebrospinal fluid compartments are thought to communicate, equalisation of fluid via the chiasmal cistern would have been expected to occur. The MRI scan of the brain and orbits, however, demonstrated localised and isolated stasis of fluid in the right optic nerve subarachnoid space only. The reason for this fluid congestion causing a optic nerve sheath compartment syndrome could not be identified by neuroimaging. The site of inflammation of the optic nerve and local anatomical variations and alterations of the subarachnoid space-for example, the amount and number of trabecula

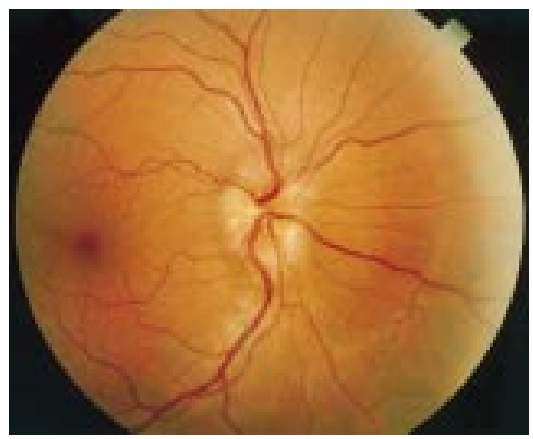

Figure 2 Fundus photograph of the right eye demonstrating a prominent optic disc with blurred margins and nerve fibre obscuration in the superior and temporal quadrant. Patton folds are observed extending to the macula. The veins appear engorged. and septae in the subarachnoid space, ${ }^{5}$ may have a crucial role in the pathophysiology of unilateral papilloedema.

H E Killer, A Mironov Department of Ophthalmology and Radiology, Kantonsspital Aarau, Switzerland

J Flammer

University Eye Clinic, Basel, Switzerland

Correspondence to: H E Killer, MD, Augenklinik, Kantonsspital Aarau, Aarau, Switzerland; Killer@KSA.ch

Accepted for publication 9 August 2002

\section{References}

1 Brodsky M, Vaphiades M. Magnetic resonance imaging in pseudotumor cerebri. Ophthalmology 1998;105: 1686-93.

2 Jinkins JR. Optic hydrops: isolated nerve sheath dilation demonstrated by CT. Am J Neuroradiol 1987;8:868-70.

3 Killer HE, Flammer J. Unilateral papilledema caused by a fronto-temporo-parietal arachnoid cyst. Am J Ophthalmol 2001;132:589-91.

4 Spoor TC, Mc Henry JG, Lau-Sickon L. Progressive and static nonarteritic ischemic optic neuropathy treated by optic nerve sheath fenestration. Ophthalmology 1993;100:306-1 1

5 Killer HE, Laeng HR, Groscurth P. Lymphatic capillaries in the meninges of the human optic nerve. J Neuro-Ophthalmol 1999;19:222-8.

\section{MAILBOX}

\section{Corneal opacification following keratoplasty in the rat model}

I read with great interest the excellent perspective by Plsková et al, ${ }^{1}$ in which they raise the issue of transient corneal opacificamouse model and argue that it might be due to a sufficient number of endothelial cells regaining function.

What the authors describe for the mouse model also occurs in the rat model. In fact, tion following corneal transplantation in the 
most researchers on the rat model probably have this experience, but for some reason do not think it is very important and/or choose to ignore it. Apart from the article by Williams $e$ $a l^{2}$ there is - as far as I know-only one other author who has explicitly mentioned this transient opacification. In their paper, Herbort et $a l^{3}$ wrote "The grafts began clearing 4 weeks after surgery .... and vessels in the graft diminished from 6 weeks post-surgery." and "It has to be noted that after acute rejection most corneas regain some clarity by $7-8$ weeks." Transient corneal opacification also occurs in the rat model $\mathrm{I}_{\mathrm{used}}{ }^{4}$ (AO rats (strain $\mathrm{RTI}^{\mathrm{u}}$ ) served as recipients of corneas from PVG rats (strain $\mathrm{RTI}^{\mathrm{c}}$ ) and corneas were sutured with a single running suture). Allogeneic transplanted corneas showed no initial opacification immediately postoperatively; neither did the syngeneic controls. All allogeneic corneas "rejected" (or more precisely showed total opacification) around day 11-13 and those corneas, when followed long enough, all cleared. Opacification remained higher than 2 (meaning an increased corneal haze, but some anterior chamber structures still visible) at days 17-21 and became lower than 2 (slight haze) around days 2l-32.

It would be exciting to know if the hypothesis put forward by Plsková et al ${ }^{1}$ would also apply to the rat model and to find out if this "clearing" of the opacification also occurs in other rat strains than the ones mentioned.

Plsková et al have raised a very importan topic where a lot of uncertainty still exists, and which warrants further research.

Ilse Claerhout

Department of Ophthalmology, Ghent University Hospital, De Pintelaan 185,9000 Gent, Belgium; Ilse.claerhout@rug.ac.be

References

1 PIsková J, Kuffová L, Holán V, et al. Evaluation of corneal graft rejection in a mouse model. Br J Ophthalmol 2002;86:108-13.

2 Williams KA, Coster DJ. Penetrating corneal transplantation in the inbred rat; a new model. Invest Ophthalmol Vis $\mathrm{Sci}$ 1985;26:23-30.

3 Herbort CP, Matsubara M, Nishi M, et al. Penetrating keratoplasty in the rat: a model for the study of immunosuppressive treatment of graft rejection. Jpn J Ophthalmol 1989:33:212-20.

4 Claerhout I, Beele H, Verstraete A, et al. The effect of duration and timing of systemic cyclosporine therapy on corneal allograft survival in the rat model. Graefes Arch Clin Exp Ophthalmol 2001;239:152-7.

\section{Surgery for glaucoma in the 21 st century}

The authors of the article "Surgery for glaucoma in the 21 st century"1 should be commended for attempting to tackle this issue. Nevertheless, we do feel that their fundamental points and principal arguments merit reconsideration.

The authors state categorically that "This finding of a higher 'failure' rate based on intraocular pressure after 'non-penetrating' surgery compared with trabeculectomy has been a finding in the majority of randomised trials comparing the two procedures" and then go on to quote three references allegedly supporting this remark.

One of the three studies ${ }^{2}$ reports lower mean IOP with deep sclerectomy compared to trabeculectomy (although not statistically significant) and almost identical success rates. What was significant was the dramatically lower complication rates with deep sclerectomy.
When discussing the other two papers ${ }^{3}{ }^{4}$ it is of paramount importance to understand that given the long learning curve associated with deep sclerectomy, it is neither fair nor scientifically sound to compare a surgeon's last 20 cases of trabeculectomy with his first 20 cases of deep sclerectomy. As an example, one group ${ }^{4}$ reported $0 \%$ success rate in their first series of viscocanalostomy patients and then presented their second series with a success rate of $15 \%{ }^{4}$ The same group also analysed the depth of their dissection of the deep sclera ${ }^{6}$ to find that they dissected too superficially in $48 \%$ of their cases and too deeply in $17 \%$; meaning that the proper depth of dissection, which should bisect transversally the Schlemm's canal deroofing it, was not achieved in the majority of their cases.

The authors also failed to cite published long term (43.2 (SD 14.3) months) results for deep sclerectomy with collagen implant. ${ }^{7}$ The study provided a qualified success rate of $94.8 \%$ and the complete success rate, $61.9 \%$ after 60 months (survival analysis), with a mean IOP at end of follow up of 11.8 (SD 3) $\mathrm{mm} \mathrm{Hg}$. Although the study reports a non-randomised consecutive series of patient, it should be taken as a proper indication of results achieved by experienced surgeons.

It should be taken into consideration that non-penetrating surgery is a broad genre of surgery, under which different surgeons perform fundamentally different procedures that include sinusotomy, ab externo trabeculectomy, deep sclerectomy with or without the use of an implant, viscocanalostomy, performance of postoperative goniopuncture, and the use of antimetabolites. The different techniques have one thing in common, the element of non-perforation.

What is true is that this type of surgery is continuously evolving, so it is unlikely that a proper judgment can be made yet. At the risk of sounding dramatic, it is valid to say that editorials like the one by Khaw et al seem to indirectly sign a death certificate of nonpenetrating surgery. It is much more useful to encourage research in non-penetrating surgery, including multicentre randomised studies, to see if trabeculectomy will remain king.

\section{T Shaarawy}

Glaucoma Unit, Memorial Research Institute of Ophthalmology, Giza, Egypt tshaarawy@glaucoma-eg.com

\section{References}

1 Khaw PT, Wells AP, Lim KS. Surgery for glaucoma in the 21 st century. $\mathrm{Br} J$ Ophthalmol 2002:86:710-1

2 El Sayyad F, Helal M, El Kholify H, et al. Nonpenetrating deep sclerectomy versus trabeculectomy in bilateral primary open-angle glaucoma. Ophthalmology 2000;107: 1671-4.

3 Chiselita D. Non-penetrating sclerectomy versus trabeculectomy in primary open angle glaucoma surgery. Eye 2001;15:197-201

4 Jonescu-Cuypers C, Jacobi P, Konen W, et al. Primary viscocanalostomy versus trabeculectomy in white patients with open-angle glaucoma: a randomized clinical trial. Ophthalmology 2001;108:254-8.

5 Dietlein TS, Krieglstein GK. Morphology and pressure-reducing efficacy after viscocanalostomy. Paris: Closed Meeting of the European Glaucoma Society, 2001:23.

6 Dietlein TS, Luke C, Jacobi PC, et al. Variability of dissection depth in deep sclerectomy: morphological analysis of the deep scleral flap. Graefes Arch Clin Exp Ophthalmol 2000;238:405-9

7 Shaarawy T, Karlen M, Schnyder C, et al. Five-year results of deep sclerectomy with collagen implant. J Cataract Refract Surg 2001;27: 1770-8.

\section{NOTICES}

\section{Role of optometry in Vision 2000}

The latest issue of Community Eye Health (No 43) discusses the mobilisation of optometry to deal with uncorrected refractive error, which is now a major cause of functional blindness. For further information please contact: Journal of Community Eye Health, International Centre for Eye Health, Institute of Ophthalmology, 11-43 Bath Street, London ECIV 9EL, UK (tel: +44 (0)20 7608 6910; fax: +44 (0)20 7250 3207; email: eyeresource@ucl.ac.uk; web site: www.jceh.co.uk). Annual subscription (4 issues) UK£25/US\$40. Free to workers in developing countries.

\section{International Centre for Eye Health}

The International Centre for Eye Health has published a new edition of the Standard List of Medicines, Equipment, Instruments and Optical Supplies (2001) for eye care services in developing countries. It is compiled by the Task Force of the International Agency for the Prevention of Blindness. Further details: Sue Stevens, International Centre for Eye Health, 11-43 Bath Street, London ECIV 9EL, UK (tel: +44 (0)20 7608 6910; email: eyeresource@ucl.ac.uk).

\section{Second Sight}

Second Sight, a UK based charity whose aims are to eliminate the backlog of cataract blind in India by the year 2020 and to establish strong links between Indian and British ophthalmologists, is regularly sending volunteer surgeons to India. Details can be found at the charity web site (www.secondsight.org.uk) or by contacting Dr Lucy Mathen (lucymathen@ yahoo.com)

\section{SPecific Eye ConditionS (SPECS)}

SPecific Eye ConditionS (SPECS) is a not for profit organisation which acts as an umbrella organisation for support groups of any conditions or syndrome with an integral eye disorder. SPECS represents over fifty different organisations related to eye disorders ranging from conditions that are relatively common to very rare syndromes. We also include groups who offer support of a more general nature to visually impaired and blind people. Support groups meet regularly in the Boardroom at Moorfields Eye Hospital to offer support to each other, share experiences, and explore new ways of working together. The web site www.eyeconditions.org.uk acts as a portal giving direct access to support groups own sites. The SPECS web page is a valuable resource for professionals and may also be of interest to people with a visual impairment or who are blind. For further details about SPECS contact: Kay Parkinson, SPECS Development Officer (tel: +44 (0)1803 524238; email: k@eyeconditions.org.uk; web site: www.eyeconditions.org.uk)

\section{The British Retinitis Pigmentosa Society}

The British Retinitis Pigmentosa Society (BRPS) was formed in 1975 to bring together people with retinitis pigmentosa and their families. The principle aims of BRPS are to raise funds to support the programme of medical research into an eventual cure for this hereditary disease, and through the BRPS 
welfare service, help members and their families copy with the everyday concerns caused by retinitis pigmentosa. Part of the welfare service is the telephone helpline $(+44$ (0) 1280860363 ), which is a useful resource for any queries or worries relating to the problems retinitis pigmentosa can bring. This service is especially valuable for those recently diagnosed with retinitis pigmentosa, and all calls are taken in the strictest confidence. Many people with retinitis pigmentosa have found the Society helpful, providing encouragement, and support through the Helpline, the welfare network and the BRPS branches throughout the UK. (tel: +44 (0)1280 821 334; email: lynda@brps.demon.co.uk; web site: www.brps.demon.co.uk)

\section{Detachment Course with} international faculty on: Retinal and Vitreous Surgery with Case Presentations preceding Retina Meeting

The detachment course with international faculty on: Retinal and Vitreous Surgery with Case Presentations and the Retina Meeting will be held 14-15 March 2003 and 16 March 2003 respectively, in Mexico City, Mexico. Fur ther details: Scientific programme: Prof Ingrid Kreissig, University of Tuebingen, Schleichstr 12, Breuningerbau, 72076 Tuebingen, Germany (tel: +49 7071 295209; email ingrid.kreissig@med.uni-tuebingen.de).

Local organisation: Prof. Quiroz-Mercado, Prof. Munoz, and Prof. Gonzalez "Hospital Luis Sanchex Bulnes", Asociacion para Evitar la Ceguera en Mexico Vicente Garcia Torres \#46, Coyoacan, Mexico DF 04330 (fax: +5255 5659 5928; email: retinamex@yahoo.com).

\section{6th Annual Meeting of German Ophthalmic Surgeons}

The 16th Annual Meeting of German Ophthalmic Surgeons will be held 8-11 May 2003 in Nürnberg, Germany, Messezentrum. Organised by the Professional Association of German Ophthalmologists Ophthalmic Surgery Group the conference will cover catarac surgery, refractive surgery, glaucoma surgery, vitreoretinal surgery, corneal surgery, eye surgery in developing countries, and orbita lacrimal and lid surgery. Further details: MCN Medisinische Congress organisation Nürnberg AG, Zerzabelshofstr 29, 90478 Nürnberg, Germany (tel:+49 911 3931621; fax: +49 911 3931620; email: doc@mcnag.info; web site: www.doc-nuernberg.de)

\section{3rd British Oculoplastic Surgery Society Meeting}

The 3rd British Oculoplastic Surgery Society Meeting will be held 18-19 May 2003 in Birmingham, UK. For further details please contact the Secretary of the British Oculoplastic Surgery Society Jane Olver (tel: +44 (0)121 424 5464; fax: +44 (0)121 4244464 email: MartiDi@heartsol.wmids.nhs.uk; web site: www.bopss.org).

\section{3th Meeting of the EASD Eye Complication Study Group}

The 13th Meeting of the EASD Eye Complication Study Group will be held on the 23-25 May 2003, in Prague, Czech Republic. The scientific programme includes keynote lectures from Professor John H Fuller (UK) on The epidemiology of diabetic retinopathy; Dr $\mathrm{P}$ Martin van Hagen (The Netherlands) on
Growth factors and diabetic retinopathy; Professor Terezie Pelikanova (Czech Republic) on Pathophysiology of diabetic microvascular complications; Dr Tomas Sosna (Czech Republic) on Risk and protective factors of diabetic retinopathy.

Three travel grants of $€ 1000$ each, sponsored by GlaxoSmithKline for young scientists (under 35 years at the time of the meeting). Applications should be made with the submission of abstracts. The deadline for abstracts is 14 February 2003.

Further details: Ortopedicke Centrum, s.r.o., Strekovské nabrezi 51, 40003 Usti nad Labem, Czech Republic (tel: +420 47521 6588; fax: +420 4753340 77; email: ortcentrum-ul@volnv.cz; web site: www. ortopedicke-centrum.cz)

\section{Detachment Course with} international faculty on: Retinal and Vitreous Surgery with Case Presentations preceding the Annual Meeting of Iranian Society of Ophthalmology

The detachment course with international faculty on: Retinal and Vitreous Surgery with Case Presentations preceding Annual Meeting of Iranian Society of Ophthalmology will be held on 29-30 November 2003 and 1-4 December 2003 respectively, at the Razi Conference Center, Hemmat Hyw, Tehran, Iran. Further details: Scientific programme Prof Ingrid Kreissig, University of Tuebingen, Schleichstr. 12, Breuningerbau, 72076 Tuebingen, Germany (tel: +49 7071 295209; email: ingrid.kreissig@med.uni-tuebingen.de) Local organisation: Dr Arman Masheyekhi, Dr Siamak Moradian, Dept of Ophthalmology, Labbanfinejad Medical Center, Pasdaran Ave, Boostan 9, Tehran, 16666, Iran (fax: +98 21 254 9039; email: labbafi@hotmail.com). 